OPEN ACCESS

Edited by:

Zhang-Jin Zhang,

The University of Hong Kong,

Hong Kong

Reviewed by:

Kurt Leroy Hoffman,

Autonomous University of

Tlaxcala, Mexico

Stefania Schiavone,

University of Foggia, Italy

*Correspondence:

Tahiana Ramaholimihaso

tramaholimihaso@chu-reims.fr

Specialty section:

This article was submitted to

Psychopharmacology,

a section of the journal

Frontiers in Psychiatry

Received: 14 June 2020

Accepted: 28 October 2020

Published: 27 November 2020

Citation:

Ramaholimihaso T, Bouazzaoui F and Kaladjian A (2020) Curcumin in

Depression: Potential Mechanisms of

Action and Current Evidence-A

Narrative Review.

Front. Psychiatry 11:572533.

doi: 10.3389/fpsyt.2020.572533

\section{Curcumin in Depression: Potential Mechanisms of Action and Current Evidence-A Narrative Review}

\author{
Tahiana Ramaholimihaso*, Fayçal Bouazzaoui and Arthur Kaladjian \\ Psychiatry Department, University Hospital, Reims, France
}

Major depressive disorder (MDD) is one of the most prevalent and debilitating disorders. Current available treatments are somehow limited, so alternative therapeutic approaches targeting different biological pathways are being investigated to improve treatment outcomes. Curcumin is the main active component in the spice turmeric that has been used for centuries in Ayurvedic medicine to treat a variety of conditions, including anxiety and depressive disorders. In the past decades, curcumin has drawn researchers' attention and displays a broad range of properties that seem relevant to depression pathophysiology. In this review, we break down the potential mechanisms of action of curcumin with emphasis on the diverse systems that can be disrupted in MDD. Curcumin has displayed, in a number of studies, a potency in modulating neurotransmitter concentrations, inflammatory pathways, excitotoxicity, neuroplasticity, hypothalamic-pituitary-adrenal disturbances, insulin resistance, oxidative and nitrosative stress, and endocannabinoid system, all of which can be involved in MDD pathophysiology. To date, a handful of clinical trials have been published and suggest a benefit of curcumin in MDD. With evidence that is progressively growing, curcumin appears as a promising alternative option in the management of MDD.

Keywords: curcumin, turmeric, depression, mechanism of action, neuroprotective agent, inflammation, NLRP3, dietary supplement(s)

\section{INTRODUCTION}

Major depressive disorder (MDD) is the most common psychiatric disorder (1). In 2017, the World Health Organization announced that indeed depression was the leading cause of disability and ill health worldwide, with more than 300 million people living with depression (2).

Major depressive disorder is characterized, by the 5th Edition of the Diagnostic and Statistical Manual of Mental Disorders (DSM-5), by a depressed mood, loss of energy, a markedly diminished interest or pleasure, psychomotor retardation (or agitation), feelings of worthlessness or excessive or inappropriate guilt, insomnia or hypersomnia, significant weight loss, diminished ability to concentrate, and recurrent thoughts of death.

The MDD pathophysiology is recognized as being complex, ranging from genetic predispositions to interactions between environmental factors, and multiple biological systems. Among those, we can name disruption in the monoamine systems, which has been the prime hypothesis in MDD pathophysiology, as well as neurodegenerative processes, notably through hypothalamic-pituitary-adrenal (HPA) changes or inflammatory processes (3). 
The management of MDD has long been based on psychological interventions, and although guidelines presently suggest to practitioners to combine psychological interventions and pharmacological treatments, the discovery of antidepressant medications has made them a staple in MDD management. However, as decades have gone by, the development of antidepressants somehow reached a plateau. Although they proved to be effective (4), they are still not optimal as we can see remission rates of around 30\% after a first-line selective serotonin reuptake inhibitor therapy (5) and a cumulative remission rate of only $70 \%$ after a fourth line of pharmacological treatment (6). Moreover, lack of adherence to antidepressant medications is frequently observed, the presence of side effects being a major cause of this non-compliance.

The problem of treatment resistance has underscored the need for new management strategies, and as concepts and views on MDD pathophysiology have evolved, so have therapeutic alternatives. For this reason, we could see a growth of neurostimulation in the past decades (7) as well as the role of physical activity in the management of $\operatorname{MDD}(8$, 9). Consequently, interest in complementary and alternative medicine has been growing.

As for alternative medicines, anti-inflammatory, antioxidants, and neuroprotective compounds thought to counteract the degenerative processes frequently associated with MDD have been a new concern of exploration for treatment or adjuvant therapy. Notably, the Canadian Network for Mood and Anxiety Treatments clinical guidelines recently inserted some alternative medicines such as omega 3, acetyl L carnitine, Lavandula, or saffron among adjunctive treatments for the management of MDD in adults (9).

Turmeric (Curcuma longa) is a yellow spice, part of the ginger family (Zingiberacear). It has been empirically used for centuries in Ayurvedic and traditional Chinese medicine in a wide variety of diseases and conditions (10). Research conducted in the last half century has revealed that the active compounds of turmeric were curcuminoids, which are polyphenolic pigments that give turmeric its yellowish color. Curcumin is the primary curcuminoid and main active component in turmeric and the compound for which most studies have been done.

In the past decades, there has been a surge of interest in curcumin as evidence about its efficacy in a wide variety of diseases is growing, including cardiovascular, autoimmune, and neurodegenerative diseases as well as diabetes and cancers $(11,12)$.

Thus, curcumin displays a broad range of properties that are relevant in the pathophysiology of depression. It has been demonstrated to possess an antidepressant activity in various animal models as well as in clinical trials. A dozen randomized controlled clinical trials have indeed been conducted (13), altogether suggesting that curcumin may be effective as a treatment (or adjunct treatment) of MDD via multiple mechanisms of action.

We will discuss in this review the potential mechanisms of action underlying the efficacy of curcumin in depression, giving us an overview of the current concepts in the pathophysiology of depression, and we will also discuss the existing evidence of the efficacy of curcumin in the treatment of depression.

\section{CURCUMIN AND NEUROTRANSMITTERS}

\section{Curcumin and Monoamines}

The monoamine deficiency theory has been the primal causative model of major depression and has accompanied the rise of antidepressants. The current pharmacologic arsenal is based on this theory as the main antidepressants, such as selective serotonin reuptake inhibitors, serotonin-noradrenaline reuptake inhibitors, and monoamine oxidase (MAO) inhibitors, are designed to increase the availability of monoamines (serotonin, noradrenaline, dopamine). According to this theory, it is thought that the depletion of these neurotransmitters in the central nervous system (CNS) constitutes the core of depression pathophysiology (14).

Evidence of curcumin being able to influence levels of monoamines in the central nervous system has emerged from animal and in vitro studies conducted over the past two decades. In a study, Bhutani et al. (15) showed that curcumin reversed the depressive-like behavior induced by chronic stress on mice and enhanced the serotoninergic and dopaminergic transmission alongside an inhibition of the MAO-A. Kulkarni et al. (16) had similar results in a study on rats in which curcumin dose-dependently increased serotonin and dopamine as well as inhibited the monoamine oxidase enzymes. More recent studies also showed that curcumin could elevate norepinephrine, serotonin, and dopamine in the frontal cortex, hippocampus, and striatum in rats $(17-22)$.

Wang et al. (23), in an animal study on the effects of curcumin on serotonin $(5-\mathrm{HT})$ receptors, stated that the antidepressantlike effect that they could notice was related to the serotoninergic system, possibly due to an interaction with 5-HT1A/1B and 5HT2C receptors. Similarly, Xu et al. (24) conducted a study in which the antidepressant effect of curcumin seemed related to the expression of 5-HT1A receptors, as 5-HT1A receptor mRNA levels across all hippocampal subfields were increased after curcumin administration. These results have been replicated by more recent studies like by $\mathrm{Li}$ et al. (25) or Lian et al. (26) in which they noticed an upregulation of 5-HT1A receptor expression after curcumin administration in chronically stressed mice and a prevention of its antidepressant-like effect with the administration of a 5-HT1B receptor antagonist.

Taken together, these animal studies strongly support the hypothesis that curcumin can modulate monoaminergic systems in pre-clinical rodent models.

\section{Curcumin and Glutamate}

In 1959, Crane (27) made an observation that the antituberculosis agent d-cycloserine, which acts as a glutamatergic modulator, could possess an antidepressant effect, yet this observation gained little attention during the following decades until 2000, when Berman et al. (28) reported that ketamine, an antiglutamatergic anesthetic agent, could induce a rapid antidepressant effect in severely depressed patients. This triggered vigorous research to understand how 
modulating glutamate signaling could be beneficial in depression and to develop new antidepressants targeting glutamate neurotransmission. It is worth noting that ketamine has now proven its efficacy in treating depression (29).

Glutamate is the major excitatory neurotransmitter in the central nervous system and has a vital role in the regulation of synaptic plasticity. By binding to its receptors, notably NMDA receptors (NMDAR), glutamate will modulate postsynaptic plasticity as well as exert longer-term changes in synaptic strength and neuroplasticity. However, the abnormal elevation of NMDAR signaling leads to deleterious effects on neurons (30). As such, excitotoxicity is the phenomenon associated with excessive glutamate release and subsequent overactivation of NMDA receptors and has long been described (31).

A number of reports suggest that the glutamate system and excitotoxicity are involved in MDD pathophysiology. For example, glutamate levels have been shown to be elevated in the plasma, cerebrospinal fluid, and brains of patients with depression (32).

Chronic stress is believed to lead to detrimental changes within glutamate synapses, including reduced extracellular glutamate clearance by glia, especially in the pre-frontal cortex, leading to increased extrasynaptic glutamate levels and excitotoxicity, potentially contributing to synaptic loss (33). Hence, in a study conducted by Lin et al. (34), curcumin was shown to inhibit the liberation of glutamate in the rat pre-frontal cortex, counteracting this phenomenon in a similar way (yet greater) to that of fluoxetine (suggesting that "classic" antidepressants like fluoxetine also act on the glutamate pathway).

A study by Zhang et al. (35) suggested that the antiglutamatergic action of curcumin could be mediated by the GluN2B subunit of NMDA receptors. Also, they noted that the administration of a sub-effective (that did not produce antidepressant effect when administered alone) dose of curcumin produced an antidepressant-like effect when paired with a subeffective dose of fluoxetine, leading to the hypothesis of a synergistic interaction between NMDA and 5-HT receptors. These results have been clarified by further in vitro studies showing that curcumin could reverse glutamate-induced neurotoxicity on hippocampal cells and downregulate the expression of the GluN2B subunit of NMDA receptors $(36,37)$. The antagonization of the GluN2B subunit seems to have a crucial role in the effect of anti-NMDAR drugs such as ketamine, as the activation of this subunit inhibits the synthesis of certain synaptic proteins, such as brain-derived neurotrophic factor (BDNF), thus altering synaptic function (38). Hence, the antagonization of GluN2B subunit permits an enhancement of synaptic function. For instance, memantine, which is also an antagonist of NMDA receptors, after acute administration, had no effect on hippocampal BDNF and failed to show immediate antidepressant behavioral effects in an animal depression model (39). However, the prolonged administration of memantine was associated with an increase in BDNF levels and hippocampal cell proliferation while displaying antidepressant-like effects in other animal studies $(40,41)$. In studies displaying the action of curcumin on the glutamatergic system, these effects were associated with increased levels of $\operatorname{BDNF}(23,42)$ that might account for its antidepressant efficacy.

Collectively, those results suggest that an inhibitory effect of curcumin on excitotoxicity may be one of the mechanisms underlying its antidepressant effects.

\section{DEPRESSION, INFLAMMATION, AND CURCUMIN}

In the past decades, as the monoamine depletion theory has been the prime model of depression pathophysiology, other hypotheses have emerged. One of them implies that inflammation has a key role in depression pathophysiology. This hypothesis was prompted by the comparison we can make between "sickness behavior" and depression symptoms like anorexia, reduction of locomotor activity, anhedonia, and cognitive disturbances (43) which can be found in both conditions, and some studies showed that these types of symptoms in depression were positively correlated with Creactive protein levels (CRP) $(44,45)$. Furthermore, some reports pointed the elevation of inflammatory cytokines [mainly interleukin-1 (IL-1), interleukin-6 (IL-6), and tumor necrosis factor- $\alpha(\mathrm{TNF}-\alpha)]$ in depression (46-48). A metaanalysis displaying a reduction of inflammatory cytokine levels after antidepressant medication administration brought further support for the relationship between depression and inflammation (49). There have also been studies showing that cytokines or CRP levels could predict the antidepressant effect of the therapeutics used, including antidepressant medication (50, 51), physical exercise (52), or electroconvulsive therapy (53). While the meta-analysis performed did not show increased inflammation in every patient, its presence may be relevant to a subset of patients $(45,54)$, especially since it can guide the therapeutics.

\section{Curcumin and Immunoinflammatory Pathways}

As stated in the introduction, most of the first studies trying to unravel the beneficial effects of curcumin came from research on cancer and inflammatory diseases, and many anti-inflammatory effects of curcumin are now being acknowledged (55). A number of studies have indeed shown that curcumin could inhibit TNF production by macrophages and downregulate its expression by modulation of its transcription factors. Notably, it has been shown that curcumin was able to down-modulate the activation of nuclear factor kappa beta (NF-к $\beta$ ) (56).

A study conducted by Wang et al. (57) in 2014 has reported the effects of curcumin on inflammation and depressive symptomatology in mice treated with lipopolysaccharide (LPS). This study showed that administrating curcumin reverted the depressive-like behavior and attenuated LPS-induced microglial activation and overproduction of pro-inflammatory cytokine (interleukin- $1 \beta$ and tumor necrosis factor- $\alpha$ ). It could also inhibit LPS-induced NF- $\kappa \beta$ activation in the hippocampus and prefrontal cortex (PFC). In addition, curcumin could counteract the 
increase in the levels of nitric oxide synthase and cyclooxygenase2 mRNA in the hippocampus and pre-frontal cortex. Jangra et al. (58) reported similar results, as the administration of curcumin in LPS-treated mice improved the depressive-like symptoms, reversed the depletion of glutathione level in the hippocampus, and decreased the level of pro-inflammatory cytokines (IL-1 $\beta$ and TNF- $\alpha$ ) in the hippocampus.

Fan et al. (59) showed that chronic unpredictable mild stress exposure in mice induced microglia activation and overexpression of the cytokines IL-1 $\beta$, IL- 6 , and TNF- $\alpha$ within the medial pre-frontal cortex, effects which were paralleled with neuronal structural changes. They showed that curcumin administration produced antidepressant-like actions and reversed the inflammatory responses and neuronal structural abnormalities, thus concluding that inhibiting the IL-1 $\beta$ pathway could account for curcumin efficacy.

With regards to studies of human patients, a clinical trial conducted by Yu et al. (60) showed that curcumin decreased the inflammatory cytokines IL-1 $\beta$ and TNF- $\alpha$ in depressed patients in comparison with the placebo group. Moreover, it has been shown in other clinical trials that curcumin can lower TNF- $\alpha$, IL-6, and CRP levels in patients' plasma $(56,61,62)$.

All in all, what we can draw from these studies is that curcumin permits a decrease in inflammation, acting on proinflammatory cytokine pathways, notably TNF- $\alpha$, IL-6, and IL- $1 \beta$ in the hippocampus and pre-frontal cortex.

\section{Curcumin and Inflammasome Activation}

Clinical depression is characterized by inflammatory cascades as indicated by elevated concentrations of pro-inflammatory cytokines in the serum and in the CNS tissue. Given the known action of curcumin on some immunoinflammatory pathways, the pivotal role of IL- $1 \beta$ and microglia activation in the pathophysiology of depression, and the relevance of these processes to the therapeutic properties of curcumin, we can highlight a probable role for the inflammasomes.

Inflammasomes are crucial components of the innate immune response that initiate immunological reactions against microbial infections, tissue injury, and other aggressions. The key inflammasome in depression is the NLRP3 inflammasome complex, which, upon activation, consists of a NOD-like receptor protein containing pyrin domain (NLRP3) associated with an adaptor protein ASC and an effector caspase-1 (63).

NLRP3 inflammasome activation is related to microglial activation. Upon initially recognizing an environmental stressor, the microglia can indeed enter in an active state and are thereafter more prone to induce a prolonged inflammatory response following the upcoming exposure to those stressors. NLRP3 inflammasome has drawn interest as an explanatory element as to why primed microglia cells display sensitivity to environmental stressors. In fact, NLRP3 inflammasome acts as a transducer of neuroinflammatory responses. A lowered threshold for NLRP3 activation induces an increased production of inflammatory cytokines, such as IL-1 $\beta$ and IL-18, and then causes a persistent neuroinflammation (64). This chronic inflammation results from chronic exposure to noxious threats that negatively affect the homeostatic feedback mechanisms. In sum, NLRP3 inflammasome is a molecular mechanism that translates psychological stressful stimuli into inflammatory responses.

The activation of the NLRP3 inflammasome relies on a twostep mechanism. It requires a priming signal to initiate the transcription of the NLRP3 inflammasome to above a certain threshold, while a second signal will then promote the formation of the NLRP3 inflammasome by recruiting ASC and pro-caspase1 proteins.

The priming of NLRP3 transcription is mediated by NF- $\kappa \beta$ activation, which can result from the stimulation of membranebound receptors by TNF or pathogen-associated molecular patterns like LPS (63) or damage-associated molecular patterns whose presence indicates cellular or metabolic stress. It is worth noting that there were some reports indicating that corticosterone may also stimulate the transcription of NLRP3 via glucocorticoid receptor activation, involving the NF- $\kappa \beta$ pathway but also independently of NF-к $\beta$ activation $(65,66)$.

Another way of activating NLRP3 inflammasome is the reduction of intracellular potassium $(\mathrm{K}+)$ levels via the activation of the P2X7 purinergic receptors. Extracellular ATP is released by neurons and astrocytes following excitotoxicity. Activation of these receptors causes potassium efflux in microglia, which is crucial for the activation of the NLRP3 inflammasome (67). Besides that, $\mathrm{P} 2 \mathrm{X} 7$ receptor is being investigated as a potential drug target in mood disorders (68). Reactive oxygen species (ROS) can also promote NLRP3 activation (69). An activated NLRP3 inflammasome will then cleave pro-IL-1 $\beta$ and pro-IL-18 into active IL- $1 \beta$ and IL-18.

There have been a few studies highlighting the role of NLRP3 inflammasome in depression. Animal studies investigating this theory showed that chronic stress could stimulate NLRP3 activation in rodent brains and that, accordingly, in the absence of the NLRP3 inflammasome activation, stress did not produce a depressive behavior, anhedonia, or social impairment in those mice (70-73). It has also been shown that NLRP3 is activated in mononuclear cells in patients with depressive disorder and that some antidepressants compounds seem to show a decrease in NLRP3 activation (74).

Concerning curcumin, in an in vitro study conducted by $\mathrm{Li}$ et al. (75) on rat hippocampal cells, excessive glutamate release induced IL-1 $\beta$ secretion and generation of ROS. Curcumin was able to inhibit the generation of ROS and NLRP3 inflammasome activation assessed by NLRP3 and caspase-1 expression, which resulted in a reduction of IL-1 $\beta$ secretion. In addition, curcumin could prevent glutamate-induced cell apoptosis. In the same vein, Fan et al. (76) showed that curcumin administration could prevent IL- $1 \beta$-induced apoptosis in stressed rats in the ventromedial pre-frontal cortex and alleviate depressive behavior.

In a study conducted by Zhang et al. (77), rats were exposed to chronic unpredictable stress, and this exposure led to depressive-like behaviors. Curcumin successfully corrected the depressive-like behaviors in those stressed rats. Additionally, curcumin could effectively decrease the mRNA expression of proinflammatory cytokines (IL-1 $\beta$, IL-6, and TNF- $\alpha$ ) and suppress NF- $\kappa \beta$ activation as well as inhibit the expression of 
P2X7 receptors, thus preventing NLRP3 activation. These results were in accord with a study conducted by Wang et al. (78), in which curcumin could inhibit the activation of the $\mathrm{P} 2 \mathrm{X} 7$ receptor and thus inhibit the inflammatory response and the microglial activation, thus preventing NLRP3 activation.

It is also worth quoting a recent study conducted by Ozkartal et al. (73) that highlighted the role of nitric oxide synthase (NOS) in the activation of NLRP3 inflammasome; in this study, the administration of NOS inhibitors in chronically stressed mice prevented the activation of NLRP3 inflammasome and the production of IL- $1 \beta$.

In some reports, depression has been associated with an excessive activity of nitric oxide synthase (79). Also, some antidepressant medications in current use, such as paroxetine, inhibit NOS activity (80). In some other studies, suicidal and depressed patients had elevated levels of plasma $\mathrm{NO}$ and its metabolites $(81,82)$. The overactivation of NOS pathway and subsequently increased nitric oxide has been described as an important pathophysiological factor in neuroinflammation and neurotoxicity processes involved in stress and depression $(79,83)$ as well as an important modulating factor in the production of neurotransmitters such as noradrenaline, serotonin, and dopamine (79), thus explaining why NOS inhibitors can exert antidepressant and anxiolytic-like effects $(73,84)$.

In human cultured neurons exposed to quinolinic acid, quinolinic acid increased NOS activity and consequently increased the nitrite levels. In those neurons, curcumin could counteract this increase of NOS activity (85). Studies investigating the influence of curcumin on NOS pathway in animal models have shown that, in rat (86) or pig (87) stress models, curcumin could inhibit NOS hyperactivation and the subsequent increase in hippocampal NO. As previously cited in the study conducted by Wang et al. (57) on mice with LPSinduced depressive symptomatology, curcumin could attenuate the LPS-induced microglial activation and NF- $\kappa \beta$ activation in the hippocampus and PFC as well as decreased the levels of NOS in the hippocampus and PFC.

These data suggest that NLRP3 activation can play a major role in inflammatory-related depressive symptoms and that its inhibition by curcumin might be a key feature of its effectiveness.

\section{Curcumin and Kynurenine Pathway}

Indoleamine 2,3-dioxygenase (IDO) is an enzyme that is strongly activated by proinflammatory cytokines (such as TNF- $\alpha$, IL-1, and IL-6) (88). This enzyme has an important role in depression by catabolizing tryptophan (the primary precursor of serotonin) into kynurenine pathway metabolites: IDO leads to tryptophan depletion and thus inhibits serotonin synthesis. As stated before, the role of serotonin in depression is already admitted. However, research shows that kynurenine pathway metabolites can impact several mechanisms associated with depression, such as proapoptotic changes in the CNS or generation of free radicals (89). Preclinical studies have shown that IDO activation results in depressive-like symptoms and that IDO inhibitors could relieve depression-like behaviors in mice (90).

There are two main kynurenine pathway metabolites studied in depression: one of them is quinolinic acid, an NMDA agonist, that is thought to be excitotoxic, thus leading to synaptic loss. It can also disrupt the oxidant/antioxidant balance by increasing the generation of free radicals and induce lipid peroxidation (88). Excess quinolinic acid levels were found in depression (91), however inconsistently (92). The levels of quinolinic acid were still shown to predict the response to antidepressant medications such as ketamine (93). The second main kynurenine pathway metabolite is kynurenic acid, considered to be neuroprotective. Its balance with quinolinic acid is considered to be protective against the excitotoxicity of the latter (94). Moreover, studies reported lower levels of kynurenic acid in depression (92).

In vitro studies demonstrated that curcumin could counteract the inflammation-induced overexpression of IDO (95), and more recently, a study conducted by Zhang et al. (77) showed that curcumin could inhibit the stress-induced overexpression of IDO in rats and normalize the quinolinic acid/tryptophane ratio.

Another important co-factor of the increase of IDO is cyclooxygenase 2 (COX-2) (96). COX-2 is an enzyme responsible for the production of prostaglandin E2 (PGE2), which is a pro-inflammatory chemical messenger. Studies have shown an increase in PGE2 production and COX-2 expression in depressed patients $(97,98)$. The peripheral blood cells of patients with recurrent depression also exhibited an increased expression of the genes encoding for COX-2 (99). A number of clinical trials have yielded promising results for the use of COX-2 inhibitors as an augmentation of antidepressant treatments (100). Their use could also help decrease inflammatory cytokine levels (101).

Regarding curcumin, studies have shown that it can downregulate COX-2 expression and PGE2 synthesis in vitro (102) and in animal models of depression (103), highlighting its potential role as an alternative natural COX-2 inhibitor option. It is relevant to mention that COX-2 can induce NOS activity and vice versa (104). The $2014 \mathrm{Wang}$ et al. (57) study mentioned before (see the previous section) illustrates the interplay between NOS, IDO, and inflammatory cytokines.

Considering the possible role of COX-2 in depression and its role in IDO synthesis and the role of IDO in depression that we illustrated, these data suggest interesting mechanisms of action for the use of curcumin as an augmentation therapy.

\section{Curcumin and Intestine Hyperpermeability}

As the largest mucosal surface in the human body, the intestinal epithelium acts as an interface with the external environment (105). In some situations, the permeability of the intestinal epithelium can be altered in a state also called "leaky gut."

Lipopolysaccharides (LPS) are large molecules found in the outer membrane of gram-negative bacteria. In a state of "leaky gut," there will be an increased translocation of those gram-negative bacteria from the intestine into the systemic circulation and, with them, the LPS $(106,107)$. LPS can then stimulate toll-like receptors, generating an inflammatory process. This will result in pro-inflammatory cytokine secretion and neuroinflammation (108) and also activation of IDO with the previously described consequences (109-111).

Some studies have reported increased serum $\operatorname{IgM}$ and $\operatorname{IgA}$ levels directed against the LPS of gram-negative enterobacteria in depressed patients, reflecting an increased translocation 
of LPS from those gram-negative enterobacteria, with the authors of such studies concluding that depressive disorder was accompanied with intestinal hyperpermeability $(107,112)$.

In animals, LPS induces depressive behaviors (110). Thus, a number of studies investigating the anti-inflammatory effects of curcumin were carried out using LPS models. In such models, curcumin reversed LPS-induced behavioral and molecular changes. Moreover, a handful of in vitro studies have shown that curcumin could increase the expression of tight junction proteins, thus preventing the disruption of tight junction organization and decreasing LPS increase due to paracellular permeability (113).

These data suggest that one antidepressant mechanism of action of curcumin could be its ability to counteract this state of gut permeability and subsequent LPS-induced inflammation.

\section{DEPRESSION, METABOLISM, AND CURCUMIN}

\section{Curcumin and HPA Axis}

The HPA axis is a central system in the body's stress response, and abnormalities in its activity have long been noted in MDD (114). Studies have shown that depression was associated with impairment in the responsiveness to glucocorticoids and a subsequent hypersecretion of $\mathrm{CRH}$. This phenomenon is known as glucocorticoid resistance and can, in turn, prime the inflammatory response (114). We have indeed highlighted the role of corticosterone in the activation of NLRP3 inflammasome $(65,66)$. Depression is also associated with an increased size and activity of the pituitary and the adrenal glands (115).

Based on these assumptions, animal models of depression related to stress and elevated cortisol levels have been developed. In such models, curcumin has been shown to alleviate the depressive symptoms and other physiological alterations induced by cortisol.

Li et al. (25) showed that, in stressed rats, curcumin could restore the normal level of corticosterone. Rinwa and Kumar later found similar results (116). Researchers showed that curcumin could protect against corticosterone-induced neurotoxicity and downregulation of mRNA levels of serotoninergic receptors in a rodent model (5-HT1A, 5-HT2A, and 5-HT4) (117). Curcumin could also normalize the adrenal gland size in stressed rats (118). Furthermore, curcumin decreased the salivary cortisol concentrations in depressed patients compared with the placebo group in the clinical trial of Yu et al. (60).

\section{Depression, Insulin Sensitivity, and Curcumin}

Insulin receptors are present throughout the brain, and they play a central role in regulating its use of glucose for energy (119). Moreover, some of insulin's actions are specific for the CNS, like promoting neuronal survival or synaptic plasticity and regulation of brain functions including memory, cognition, learning as well as attention $(120,121)$. Insulin also inhibits norepinephrine and serotonin reuptake and downregulates alpha-2 receptor expression in hypothalamic neurons (122).
Consequently, there has been a hypothesis suggesting that insulin resistance played a role in depressive disorder pathophysiology, which was reinforced by epidemiological studies. For example, adults with insulin resistance are more at risk for the development of future depression (123), and a metaanalysis has shown an association between insulin resistance and depression incidence (124). Significantly, insulin resistance interacts with other depressogenic processes. Given the insulin functions in the brain, it has also been shown that reduced brain sensitivity to insulin can manifest as impaired neuroplasticity and disturbances in neurotransmitter's release and uptake (125). Insulin resistance has also been shown to be associated with altered dopamine signaling in rodents (126).

Inflammation and oxidative stress are both involved in the pathogenesis of insulin resistance $(127,128)$. In turn, insulin has antioxidant properties which become disrupted following insulin resistance (129). As described earlier, oxidative stress resulting from the disruption of insulin functions can, in turn, trigger the production of pro-inflammatory cytokines. The desensitization of glucocorticoid receptors that can be associated with insulin resistance (130) may potentiate this depressogenic cascade.

There is an emerging research field trying to reposition some antidiabetic medications as new means in depression management like GLP1 functional agonists, pioglitazone, or even metformin (131).

Concerning curcumin, Shen et al. (132) have conducted a study on mice with unpredictable chronic mild stress in which they showed that curcumin could attenuate insulin resistance alongside a decrease in depressive-like symptoms. There were also other studies showing the positive effects of curcumin on insulin resistance in in vitro, animal, or even human studies (133).

\section{DEPRESSION AND NEUROPLASTICITY, CURCUMIN, AND NEUROPROTECTION}

The 1990s witnessed the rise of the "neurotrophic" hypothesis of depression, which associated chronic stress and depression with a deficit in BDNF and demonstrated that traditional antidepressants increased BDNF expression (134). Hence, by the early 2000s, studies progressively exhibited increasing evidence of the presence of cellular atrophy and neuronal death in major depressive disorder. Studies also showed increased growth factor (such as BDNF) levels associated with antidepressant therapies such as physical exercise (135), antidepressants (136), electroconvulsive therapy (137), or lithium (138). This supports the hypothesis that the neurotrophic effects of antidepressants account for their efficacy in treating MDD, with some authors even viewing $\mathrm{BDNF}$ as an essential determinant of antidepressant efficacy (136).

We have already underlined the neuroprotective effect that curcumin could exert $v i a$ its inhibition of inflammatory pathways and the mitigation of glutamate excitotoxicity $(59,76)$. This is particularly illustrated by a study conducted by Choi et al. (103) in which curcumin administration permitted an improvement of the depressive behavior induced by chronic unpredictable 
stress in mice alongside reduced hippocampal neuronal cell death, attenuated long-term depression, increase in BDNF, and COX-2 inhibition, suggesting neuroprotection via antiinflammatory effects. Curcumin can also exert neuroprotective effects by stimulating the production of neurotrophic factors, especially BDNF.

The extracellular signal-regulated kinase (ERK) is a subfamily of mitogen-activated protein kinase (MAPK), an essential family of serine/threonine kinase regulating cellular growth, differentiation, and survival in proliferative cells including brain cells (139). ERK, alongside BDNF, has shown to be downregulated in the PFC and hippocampus of depressed humans and animals, and antidepressants could, in turn, reverse the hypoactivity of ERK and alleviate depression-like behaviors. Reciprocally, in animal studies, blocking the BDNF pathway resulted in a loss of effects of antidepressants (140).

The transcription factor CREB is also a downstream target of ERK, and other studies found that CREB phosphorylation was decreased in the frontal cortex and the hippocampus of stressed humans and animals, accompanied with a decrease in ERK activity. Antidepressants reversed the reduction of CREB phosphorylation in stressed animals (140). In short, the activation of the ERK pathway by antidepressants increases the expression of nuclear CREB, which facilitates the expression of neurotrophic/neuroprotective proteins such as the BDNF.

In an adult male Wistar-Kyoto rat model of depression, Hurley et al. (141) showed that curcumin had an antidepressant activity and found an increase in hippocampal BDNF. Similarly, $\mathrm{Xu}$ et al. (24) showed that administrating curcumin to chronically stressed mice increased the hippocampal BDNF. Liu et al. (142) showed similar results in chronically stressed mice with a positive effect on stress-induced learning and memory deficits and an upregulation of BDNF and ERK in the hippocampus.

Some authors have also shown a neuroprotective effect of curcumin in the amygdala. For example, Zhang et al. (143) showed in a study that curcumin could increase BDNF levels in rat amygdala via ERK phosphorylation and alleviate depressive behavior. They later replicated those results (144). Similarly, Abd-Rabo (145) could show that the administration of curcumin in ovariectomized rats could alleviate depressive behavior and upregulate the BDNF mRNA in the limbic system. With regards to human studies, Yu et al. (60) showed, in a clinical trial, that curcumin increased the plasma BDNF levels compared to the placebo group.

These studies suggest that curcumin can alleviate depressive behavior through activation of the ERK/BDNF neurotrophic pathway, especially in the hippocampus, the pre-frontal cortex, or the amygdala that are involved in depression pathophysiology.

\section{OXIDATIVE STRESS, DEPRESSION, AND CURCUMIN}

As stated in the introduction, depression pathophysiology may involve several interconnected biochemical pathways including nitrosative stress and oxidative stress. Generally, oxidative stress is defined as an imbalance between the production of reactive oxygen and nitrogen species as well as the efficiency of enzymatic (like catalase, glutathione peroxidase, and superoxide dismutase) and non-enzymatic (like reduced glutathione and uric acid) antioxidative systems, so cells are said to be in a state of oxidative stress when the level of reactive oxygen species exceeds the endogenous antioxidant defense mechanisms (for e.g., the enzymes catalase, glutathione peroxidase, or superoxide dismutase) (146).

Studies to date indicate that patients with depression have lower levels of antioxidative systems, and at the same time, they display an increased amount of oxidative stress markers when compared with healthy individuals $(147,148)$. Some antioxidant therapeutics, like $\mathrm{N}$-acetyl-cysteine, seem to show some effect in depression treatment (149).

Recently, Naqvi et al. (150) have shown that, on chronically stressed mice, curcumin administration could correct depressive behaviors and improve memory functions as well as improve oxidative stress as measured by the peroxidation of lipid and the antioxidant enzyme activities. Fidelis et al. (151) administrated curcumin in a model of oxidative stress induced by beta amyloid infusion in mice and noticed an antidepressant-like effect as well as a reduction of the $A \beta$-generated oxidative stress in the pre-frontal cortex, as evidenced by the reactive species levels and the superoxide dismutase and catalase activities. Rinwa and Kumar (116) exposed mice to a chronic unpredictable stress that significantly impaired the oxidative parameters (elevated malondialdehyde and nitrite concentrations and decreased glutathione and catalase levels) and mitochondrial enzyme complex activities. Those effects were reversed by the administration of curcumin; there was an improvement in the depressive-like behavior as well. Jangra et al. (58) were also previously able to show that curcumin could reverse glutathione depletion in the hippocampus induced by LPS administration. Concerning nitrogen species and nitrosative stress, we previously addressed this issue and how curcumin could oppose this noxious phenomenon by its action on NOS.

As we have stated before, oxidative stress and mitochondrial dysfunction leading to the formation of reactive oxygen species are involved with other pathophysiological mechanisms such as inflammation. As a consequence, tackling this pathogenic cascade could be an interesting way to improve treatment outcomes in depression.

\section{CURCUMIN AND THE ENDOCANNABINOID SYSTEM}

Two kinds of cannabinoid (CB) receptors have been found in the human body: CB1 and CB2 receptors. They can activate multiple cell signaling pathways to regulate the neurotransmitter release process (152). CB1 receptors are mainly distributed in the central nervous system and may be related to the cannabinoid functions of memory and cognition regulation as well as motor control and show relatively low expression levels in the peripheral nervous system (153). On the other hand, CB2 receptors are mostly distributed in peripheral immune cells, mainly affecting immune regulation (153). 
Considering the regulatory function of $\mathrm{CB}$ receptors on mood (154) and their distribution in brain regions related to mood and reward (pre-frontal cortex, limbic system, raphe nuclei) (155), some authors proposed that the endocannabinoid signaling pathway may be involved in the formation and development of depression, as suggested by diverse animal studies showing the apparition of depressive behaviors with the blockade of CB1 receptors (156). We could also cite the example of rimonabant (a CB1 antagonist used to treat obesity) that has been forced out of the market due to anxiety and depression reported as frequent and important side effects (157) and studies reporting that the use of rimonabant could inhibit positive emotional memory as well as the reward system (158). Based on these observations, reports have also shown that the activation of $\mathrm{CB} 1$ receptors could result in similar behavior and biochemical changes as those caused by antidepressants (159).

He et al. (160) tested an association of curcumin and HU122, a cannabinoid known for having no effect on $\mathrm{CB}$ receptors. They showed some efficacy in a corticosterone-induced model of depression. The administration of this dual drug could prevent corticosterone-induced neural cell apoptosis and improve the dopamine levels, especially in the hippocampus and the striatum. Alongside those effects, the authors noted an enhanced expression of $\mathrm{CB} 1$ receptors, which could have an important role in the antidepressant potency of curcumin. Hassanzadeh and Hassanzadeh (161) suggested that the endocannabinoid system could have a pivotal role in emotion regulation and neuroplasticity exerted by curcumin as they showed in their study that chronic curcumin administration in rats could increase endocannabinoid levels as well as nerve growth factor levels in key structures like the amygdala and the hippocampus. Witkin et al. (162) noted that curcumin had no effect on depression-like behavior on $\mathrm{CB} 1 \mathrm{KO}(-/-)$ mice, highlighting the role of $\mathrm{CB} 1$ receptors in curcumin efficacy.

In sum, these data highlight the role of $\mathrm{CB} 1$ receptors as a novel and multimodal target of curcumin.

\section{TRANSLATION INTO CLINICAL PRACTICE}

To date, clinical trials have yielded conflicting results regarding the efficacy of curcumin in depression; however, there has been two meta-analyses concluding that curcumin could be effective in depression: the first one was in 2017 (163), which included six studies with a total of 377 patients comparing the use of curcumin to placebo, supporting a significant clinical efficacy in depression, and the second one was conducted by Fusar-Poli et al. (13), in which curcumin was evaluated as an add-on therapeutic, that included 10 studies with a total of 531 patients, supporting the efficacy of curcumin as an add-on.

However, even though there were moderate to large effect sizes in those meta-analysis, it is important to note that not every study yielded significant results and that the studies were heterogeneous, especially with the formulations and the dosage of curcumin used. Yet a concern about curcumin has been its bioavailability, and thus diverse formulas are being developed to enhance its bioavailability, like the use of curcumin nanoparticles, liposomal encapsulation, emulsions, lipid complexes, use of piperine, or development of synthetic curcumin analogs (164, 165). However, no statistical analysis could be performed in those meta-analysis regarding a potential difference in efficacy between formulas due to the small number of studies, so further clinical trials with diverse curcumin formulations will be important since, in animal studies, different magnitudes of effects on the behavioral, molecular, and electrophysiological levels have been reported depending on the curcumin formula administered (20, 151). Nonetheless, the meta-analyses conducted did not show significant differences with respect to the dosage of curcumin used ( $>$ or $\leq 500 \mathrm{mg} /$ day). Moreover, it is important to note that the clinical trials conducted were generally small, with samples varying from 14 to 123 (13). Thus, enlarging samples in future studies would be desirable.

Curcumin generally appears to be well-tolerated, with only mild side effects like yellow stool, headache, or diarrhea noted in doses up to $12 \mathrm{~g} /$ day (166).

On another hand, most of the studies were conducted in Asian countries, where dietary regimens usually include curcuminoids, so it would be interesting to test the effects of curcumin in Western countries to see if the dietary regimen influences curcumin potency. Nonetheless, the most convincing effects of curcumin were shown in studies conducted in Australia $(167,168)$.

Due to the poor bioavailability of curcumin, turmeric ingestion as powder might instinctively be thought unlikely to have therapeutic potency, particularly as the curcumin content of pure turmeric powder is only around 3\% (169). However, as we have previously highlighted the neuroprotective potency of curcumin, in some studies, dietary curcuminoid consumption was positively correlated with an overall better cognitive performance in the elderly (170). In fact, this lack of bioavailability could also account for curcumin efficacy via its direct effects in the intestine, as it can act on intestinal barrier dysfunction as described earlier and thus tackle the subsequent systemic inflammation. Gut microbiota can also, via demethylation, metabolize curcumin into active metabolites, such as methexylcurcumin that has been evaluated as a potential effective synthetic analog, so the metabolization by gut microbiota into active metabolites may also exert systemic effects (171). Primarily targeting enterocytes because of this lack of bioavailability and a subsequent extensive first-pass metabolism may also account for the increased efficacy of co-administered drugs (172), supporting the use of curcumin as an add-on agent. Giving further arguments to this hypothesis, Lopresti et al. (173) have conducted a clinical trial in which the basal levels of endothelin-1 were predictive of a greater effect of curcumin administration on depressive symptoms (assessed by the inventory of depressive symptomatology). Since endothelin1 has shown in rat models that it had a role in bacterial translocation (174), this supports the fact that ameliorating intestinal permeability and bacterial translocation may play an important role in curcumin antidepressant efficacy. The basal levels of endothelin-1 may also reflect the systemic effects of curcumin as endothelin-1 influences oxidative stress (175), HPA activity (176), and cytokine production (177). 


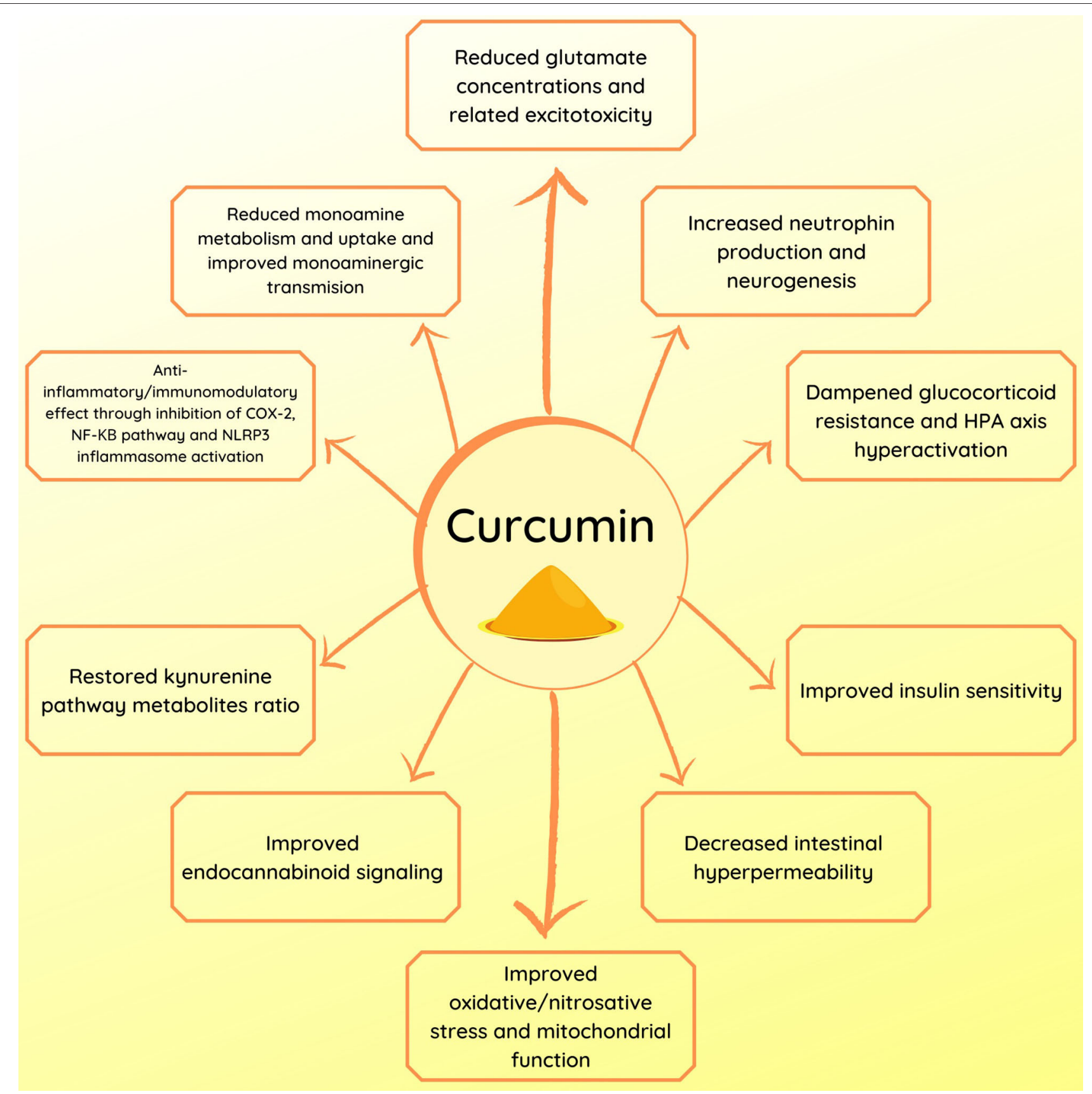

FIGURE 1 | Summary of the potential mechanisms of action of curcumin in depression.

Although curcumin has displayed an efficacy as monotherapy in placebo-controlled trials (163) or in antidepressant-controlled trials (178), this study of Lopresti et al. (173) raises the question of the subset of patients in which curcumin could be beneficial. Since curcumin has been studied in various diseases, especially inflammatory diseases, perhaps curcumin could be beneficial in patients with comorbidities. There have been two studies evaluating the use of curcumin in such conditions. The first was an 8-week randomized, double-blind, placebo-controlled trial conducted by Asadi et al. (179), testing the efficacy of curcumin on depression and anxiety in diabetic patients with polyneuropathy and showing a significant reduction of depression and anxiety in the curcumin group. The second was a 4-week randomized, double-blind, placebo-controlled trial (180) testing the antidepressant effects of curcumin in patients with systemic lupus erythematosus and that yielded positive results. There was also a positive correlation between TNF- $\alpha$ levels and depressive symptoms (assessed with the 


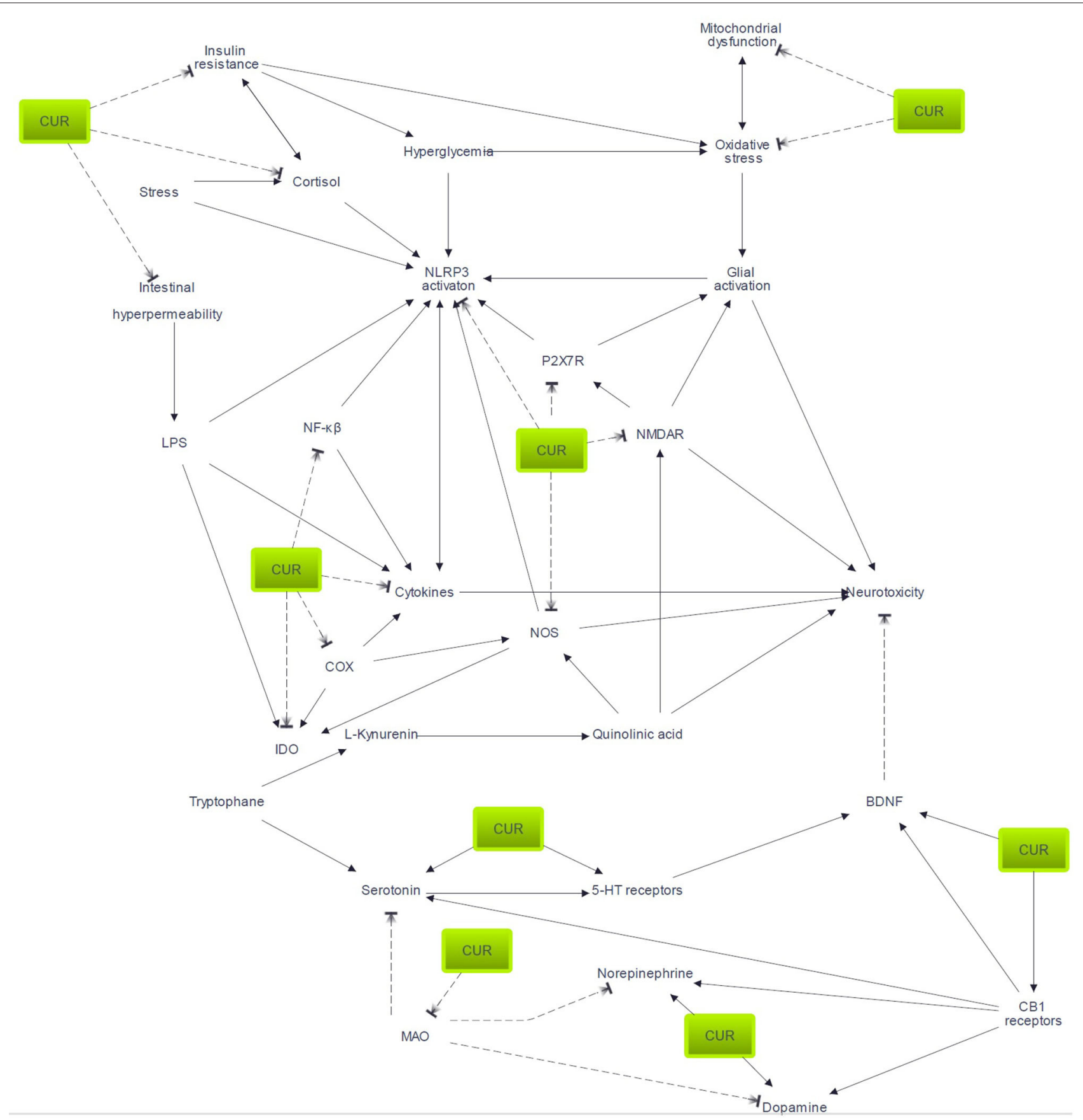

FIGURE 2 | Pathways potentially involved in curcumin efficacy. Arrow indicates activation or enhancement; broken line indicates inhibitory action. 5-HT, serotonin; BDNF, brain-derived neurotrophic factor; CUR, curcumin; COX, cyclo-oxygenase; IDO, indoleamine 2,3-dioxygenase; LPS, lipopolysaccharide; MAO, monoamine oxidase; NMDAR, N-methyl-D-aspartate receptors; P2X7R, P2X7 receptor.

Beck depression inventory) that both decreased with curcumin administration. By analogy, in a meta-analysis on patients with chronic inflammatory conditions, anti-cytokine agents exhibited an antidepressant effect, especially on severely depressed patients, that was not associated with improvement in primary physical illness (181). This highlights the fact that assessing the inflammatory status of patients may be of relevance when treating patients with curcumin since immuno-inflammatory dysregulation may account for the increased efficacy of curcumin in some patients due to its anti-inflammatory properties. This hypothesis is supported by a clinical trial in which curcumin showed a greater efficacy in patients displaying 
"atypical" depressive symptoms (168). These symptoms are defined as leaden palsy, hypersomnia, and increased appetite, symptoms that are associated with higher levels of CRP (45). In sum, although further trials are needed, curcumin could be used in a personalized fashion in which using markers such as high-sensitive CRP could serve a biomarker-based personalized antidepressant treatment selection based on patient inflammatory status before treatment, as it has been described as a predictive factor of efficacy of certain treatments $(50,51,182)$.

\section{CONCLUSION AND PERSPECTIVES}

In this review, we highlighted the wide range of targets and modes of action of curcumin. However, as many as they are (as summarized in Figure 1), they are also interconnected (as shown in Figure 2). This illustrates the complexity of depression pathophysiology that could be described as psychophysiopathologic processes. Given the diversity of pathways involved in depression, the unidimensional nature of existing pharmacologic therapeutics may be a cause for their limited efficacy. As a consequence, an enhancement of treatment efficacy is likely to occur from therapies that target multiple mechanisms. It is under this foregoing logic that curcumin may find a place as an augmentation treatment through diverse mechanisms that have been described in this review.

Given its major anti-inflammatory properties, curcumin could also be of use in a subset of patients. As inflammatory

\section{REFERENCES}

1. James SL, Abate D, Abate KH, Abay SM, Abbafati C, Abbasi N, et al. Global, regional, and national incidence, prevalence, and years lived with disability for 354 diseases and injuries for 195 countries and territories, 1990-2017: a systematic analysis for the global burden of disease study 2017. Lancet. (2018) 392:1789-858. doi: 10.1016/S0140-6736(18)32279-7

2. World Health Orgazination. Depression: Let's Talk. (2017). Available online at: https://www.who.int/news-room/detail/30-03-2017--depression-lets-talk-says-who-as-depression-tops-list-of-causes-of-ill-health (accessed May 14, 2020).

3. Malhi GS, Mann JJ. Depression. Lancet. (2018) 392:2299312. doi: 10.1016/S0140-6736(18)31948-2

4. Cipriani A, Furukawa TA, Salanti G, Chaimani A, Atkinson LZ, Ogawa $\mathrm{Y}$, et al. Comparative efficacy and acceptability of 21 antidepressant drugs for the acute treatment of adults with major depressive disorder: a systematic review and network meta-analysis. Focus. (2018) 16:4209. doi: 10.1176/appi.focus.16407

5. John Rush A, Jain S. Clinical implications of the STAR*D trial. In: Macaluso M, Preskorn SH, editors. Antidepressants: From Biogenic Amines to New Mechanisms of Action. Cham: Springer International Publishing (2019) p. 51-99.

6. Rush AJ, Trivedi MH, Wisniewski SR, Nierenberg AA, Stewart JW, Warden D, et al. Acute and longer-term outcomes in depressed outpatients requiring one or several treatment steps: a STAR*D report. Am J Psychiatry. (2006) 16:1905-17. doi: 10.1176/ajp.2006.163. 11.1905

7. Milev RV, Giacobbe P, Kennedy SH, Blumberger DM, Daskalakis ZJ, Downar J, et al. Canadian network for mood and anxiety treatments (CANMAT) 2016. Clinical guidelines for the management of adults with major depressive disorder: section 4. neurostimulation treatments. Can J Psychiatry. (2016) 61:561-75. doi: 10.1177/0706743716660033 mechanisms are relevant to some patients, those differences could account for the lack of efficacy of classical antidepressants (181).

As we have discussed in the introduction, as society evolves, patients' demands do, too. As some patients are reluctant to take medication in fear of adverse effects, alternative medicine appears to be a seductive option. Thus, curcumin could embody the dawn of nutriceuticals as anti-inflammatory and antioxidant components appear to be a possible alternative in the treatment of depression. As curcumin displays neuroprotective effects, especially against stress-induced toxicity, it also suggests the use of such molecules as prophylactic agents.

All things considered, we have highlighted that curcumin is a promising molecule as it appears to be safe and displays positive results in studies, although more clinical trials on the antidepressant effect of curcumin are still required to determine its efficacy and optimal dosage.

\section{AUTHOR CONTRIBUTIONS}

TR: original idea, literature review, and redaction. FB: supervision. All authors contributed to the article and approved the submitted version.

\section{FUNDING}

This work was supported by Institutional publishing funding.
8. Stubbs B, Vancampfort D, Hallgren M, Firth J, Veronese N, Solmi M, et al. EPA guidance on physical activity as a treatment for severe mental illness: a meta-review of the evidence and position statement from the European psychiatric association (EPA), supported by the international organization of physical therapists in mental health (IOPTMH). Eur Psychiatry. (2018) 54:124-44. doi: 10.1016/j.eurpsy.2018.07.004

9. Ravindran AV, Balneaves LG, Faulkner G, Ortiz A, McIntosh D, Morehouse RL, et al. Canadian network for mood and anxiety treatments (CANMAT) 2016. Clinical guidelines for the management of adults with major depressive disorder. Can J Psychiatry. (2016) 61:576-87. doi: 10.1177/0706743716659417

10. Aggarwal BB, Sundaram C, Malani N, Ichikawa H. Curcumin: the Indian solid gold. Adv Exp Med Biol. (2007) 595:175. doi: 10.1007/978-0-387-46401-5_1

11. Shehzad A, Rehman G, Lee YS. Curcumin in inflammatory diseases. Biofactors. (2013) 39:69-77. doi: 10.1002/biof.1066

12. Slika L, Patra D. Traditional uses, therapeutic effects and recent advances of curcumin: a mini-review. Mini Rev Med Chem. (2020) 20:107282. doi: 10.2174/1389557520666200414161316

13. Fusar-Poli L, Vozza L, Gabbiadini A, Vanella A, Concas I, Tinacci S, et al. Curcumin for depression: a meta-analysis. Crit Rev Food Sci Nutr. (2019) 60:2643-53. doi: 10.1080/10408398.2019.1653260

14. Maletic V, Robinson M, Oakes T, Iyengar S, Ball SG, Russell J. Neurobiology of depression: an integrated view of key findings. Int J Clin Pract. (2007) 61:2030-40. doi: 10.1111/j.1742-1241.2007.01602.x

15. Bhutani MK, Bishnoi M, Kulkarni SK. Anti-depressant like effect of curcumin and its combination with piperine in unpredictable chronic stressinduced behavioral, biochemical and neurochemical changes. Pharmacol Biochem Behav. (2009) 92:39-43. doi: 10.1016/j.pbb.2008.10.007

16. Kulkarni SK, Bhutani MK, Bishnoi M. Antidepressant activity of curcumin: involvement of serotonin and dopamine system. Psychopharmacology. (2008) 201:435. doi: 10.1007/s00213-008-1300-y 
17. Chang X, Wang L, Li J, Wu D. Analysis of anti-depressant potential of curcumin against depression induced male albino wistar rats. Brain Res. (2016) 1642:219-25. doi: 10.1016/j.brainres.2016.03.010

18. Lee B, Lee H. Systemic administration of curcumin affect anxiety-related behaviors in a rat model of posttraumatic stress disorder via activation of serotonergic systems. Evid Based Complement Alternat Med. (2018) 2018:9041309 doi: 10.1155/2018/9041309

19. Madiha S, Haider S. Curcumin restores rotenone induced depressivelike symptoms in animal model of neurotoxicity: assessment by social interaction test and sucrose preference test. Metab Brain Dis. (2019) 34:297308. doi: 10.1007/s11011-018-0352-X

20. Mohammed HS, Khadrawy YA, El-Sherbini TM, Amer HM. Electrocortical and biochemical evaluation of antidepressant efficacy of formulated nanocurcumin. Appl Biochem Biotechnol. (2019) 187:1096-112. doi: 10.1007/s12010-018-2866-4

21. Qi XJ, Liu XY, Tang LMY, Li PF, Qiu F, Yang AH. Antidepressant effect of curcumin-loaded guanidine-chitosan thermosensitive hydrogel by nasal delivery. Pharm Dev Technol. (2020) 25:316-25. doi: 10.1080/10837450.2019.1686524

22. Yohn SE, Gorka D, Mistry A, Collins S, Qian E, Correa M, et al. Oral ingestion and intraventricular injection of curcumin attenuates the effort-related effects of the VMAT-2 inhibitor tetrabenazine: implications for motivational symptoms of depression. J Nat Prod. (2017) 80:283944. doi: 10.1021/acs.jnatprod.7b00425

23. Wang $\mathrm{R}, \mathrm{Xu} \mathrm{Y}, \mathrm{Wu} \mathrm{HL}$, Li YB, Li YH, Guo JB, et al. The antidepressant effects of curcumin in the forced swimming test involve 5-HT1 and 5-HT2 receptors. Eur J Pharmacol. (2008) 578:43-50. doi: 10.1016/j.ejphar.2007.08.045

24. Xu Y, Ku B, Cui L, Li X, Barish PA, Foster TC, et al. Curcumin reverses impaired hippocampal neurogenesis and increases serotonin receptor $1 \mathrm{~A}$ mRNA and brain-derived neurotrophic factor expression in chronically stressed rats. Brain Res. (2007) 1162:9-18. doi: 10.1016/j.brainres.2007.05.071

25. Li YC, Wang FM, Pan Y, Qiang LQ, Cheng G, Zhang WY, et al. Antidepressant-like effects of curcumin on serotonergic receptor-coupled AC-cAMP pathway in chronic unpredictable mild stress of rats. Prog NeuroPsychopharmacol Biol Psychiatry. (2009) 33:435-49. doi: 10.1016/j.pnpbp.2009.01.006

26. Lian L, Xu Y, Zhang J, Yu Y, Zhu N, Guan X, et al. Antidepressant-like effects of a novel curcumin derivative J147: involvement of 5-HT1A receptor. Neuropharmacology. (2018) 135:506-13. doi: 10.1016/j.neuropharm.2018.04.003

27. Crane GE. Cyloserine as an antidepressant agent. AJP. (1959) 115:10256. doi: 10.1176/ajp.115.11.1025

28. Berman RM, Cappiello A, Anand A, Oren DA, Heninger GR, Charney DS, et al. Antidepressant effects of ketamine in depressed patients. Biol Psychiatry. (2000) 47:351-4. doi: 10.1016/S0006-3223(99)00230-9

29. Singh JB, Daly EJ, Mathews M, Fedgchin M, Popova V, Hough D, et al. Approval of esketamine for treatment-resistant depression. Lancet Psychiatry. (2020) 7:232-5. doi: 10.1016/S2215-0366(19)30533-4

30. Hardingham GE, Bading H. Synaptic versus extrasynaptic NMDA receptor signalling: implications for neurodegenerative disorders. Nat Rev Neurosci. (2010) 11:682-96. doi: 10.1038/nrn2911

31. Olney JW, Price MT, Fuller TA, Labruyere J, Samson L, Carpenter $M$, et al. The anti-excitotoxic effects of certain anesthetics, analgesics and sedative-hypnotics. Neurosci Lett. (1986) 68:29-34. doi: 10.1016/0304-3940(86)90224-7

32. Sanacora G, Zarate CA, Krystal JH, Manji HK. Targeting the glutamatergic system to develop novel, improved therapeutics for mood disorders. Nat Rev Drug Discov. (2008) 7:426-37. doi: 10.1038/nrd2462

33. Sanacora G, Banasr M. From pathophysiology to novel antidepressant drugs: Glial contributions to the pathology and treatment of mood disorders. Biol Psychiatry. (2013) 73:1172-9. doi: 10.1016/j.biopsych.2013.03.032

34. Lin TY, Lu CW, Wang CC, Wang YC, Wang SJ. Curcumin inhibits glutamate release in nerve terminals from rat prefrontal cortex: Possible relevance to its antidepressant mechanism. Prog Neuro Psychopharm Biol Psychiatry. (2011) 35:1785-93. doi: 10.1016/j.pnpbp.2011.06.012
35. Zhang L, Xu T, Wang S, Yu L, Liu D, Zhan R, et al. NMDA GluN2B receptors involved in the antidepressant effects of curcumin in the forced swim test. Prog Neuro Psychopharm Biol Psychiatry. (2013) 40:127. doi: 10.1016/j.pnpbp.2012.08.017

36. Khalil RM, Khedr NF. Curcumin protects against monosodium glutamate neurotoxicity and decreasing NMDA2B and mGluR5 expression in rat hippocampus. Neurosignals. (2016) 24:81-7. doi: 10.1159/000442614

37. Xu Y, Lin D, Li S, Li G, Shyamala SG, Barish PA, et al. Curcumin reverses impaired cognition and neuronal plasticity induced by chronic stress. Neuropharmacology. (2009) 57:46371. doi: 10.1016/j.neuropharm.2009.06.010

38. Miller OH, Yang L, Wang CC, Hargroder EA, Zhang Y, Delpire E, et al. GluN2B-containing NMDA receptors regulate depression-like behavior and are critical for the rapid antidepressant actions of ketamine. eLife. (2014) 3:e03581 doi: 10.7554/eLife.03581

39. Gideons ES, Kavalali ET, Monteggia LM. Mechanisms underlying differential effectiveness of memantine and ketamine in rapid antidepressant responses. Proc Natl Acad Sci USA. (2014) 111:8649-54. doi: 10.1073/pnas.1323920111

40. Takahashi K, Nakagawasai O, Nemoto W, Kadota S, Isono J, Odaira $\mathrm{T}$, et al. Memantine ameliorates depressive-like behaviors by regulating hippocampal cell proliferation and neuroprotection in olfactory bulbectomized mice. Neuropharmacology. (2018) 137:141-55. doi: 10.1016/j.neuropharm.2018.04.013

41. Amidfar M, Kim YK, Wiborg O. Effectiveness of memantine on depressionlike behavior, memory deficits and brain mRNA levels of BDNF and TrkB in rats subjected to repeated unpredictable stress. Pharmacol Rep. (2018) 70:600-6. doi: 10.1016/j.pharep.2017.12.007

42. Huang Z, Zhong XM, Li ZY, Feng CR, Pan AJ, Mao QQ. Curcumin reverses corticosterone-induced depressive-like behavior and decrease in brain BDNF levels in rats. Neurosci Lett. (2011) 493:145-8. doi: 10.1016/j.neulet.2011.02.030

43. Dunn AJ, Swiergiel AH. The role of cytokines in infectionrelated behavioral. Ann N Y Acad Sci. (1998) 840:57785. doi: 10.1111/j.1749-6632.1998.tb09596.x

44. Fried EI, Stockert S von, Haslbeck JMB, Lamers F, Schoevers RA, Penninx BWJH. Using network analysis to examine links between individual depressive symptoms, inflammatory markers, and covariates. Psychol Med. (2019) 28:1-9 doi: 10.1017/S0033291719002770

45. Jokela $M$, Virtanen $M$, Batty GD, Kivimäki M. Inflammation and specific symptoms of depression. JAMA Psychiatry. (2016) 73:87-8. doi: 10.1001/jamapsychiatry.2015.1977

46. Dowlati Y, Herrmann N, Swardfager W, Liu H, Sham L, Reim EK, et al. A meta-analysis of cytokines in major depression. Biol Psychiatry. (2010) 67:446-57. doi: 10.1016/j.biopsych.2009.09.033

47. Howren MB, Lamkin DM, Suls J. Associations of depression with C-reactive protein, IL-1, and IL-6: A meta-analysis. Psychosom Med. (2009) 71:171186. doi: 10.1097/PSY.0b013e3181907c1b

48. Liu Y, Ho RCM, Mak A. Interleukin (IL)-6, tumour necrosis factor alpha $(\mathrm{TNF}-\alpha)$ and soluble interleukin-2 receptors (sIL-2R) are elevated in patients with major depressive disorder: A meta-analysis and meta-regression. J Affect Disord. (2012) 139:230-9. doi: 10.1016/j.jad.2011.08.003

49. Hannestad J, DellaGioia N, Bloch M. The effect of antidepressant medication treatment on serum levels of inflammatory cytokines: a meta-analysis. Neuropsychopharmacology. (2011) 36:2452-9. doi: 10.1038/npp.2011.132

50. Jha MK, Minhajuddin A, Gadad BS, Greer T, Grannemann B, Soyombo A, et al. Can C-reactive protein inform antidepressant medication selection in depressed outpatients? Findings from the CO-MED trial. Psychoneuroendocrinology. (2017) 78:10513. doi: 10.1016/j.psyneuen.2017.01.023

51. Uher R, Tansey KE, Dew T, Maier W, Mors O, Hauser J, et al. An inflammatory biomarker as a differential predictor of outcome of depression treatment with escitalopram and nortriptyline. Am J Psychiatry. (2014) 171:1278-86. doi: 10.1176/appi.ajp.2014.14010094

52. Rethorst CD, Toups MS, Greer TL, Nakonezny PA, Carmody TJ, Grannemann BD, et al. Pro-inflammatory cytokines as predictors of antidepressant effects of exercise in major depressive disorder. Mol Psychiatry. (2013) 18:1119-24. doi: 10.1038/mp.2012.125 
53. Kruse JL, Congdon E, Olmstead R, Njau S, Breen EC, Narr KL, et al. Inflammation and improvement of depression following electroconvulsive therapy in treatment resistant depression. J Clin Psychiatry. (2018) 79:17m11597. doi: 10.4088/JCP.17m11597

54. Raison CL, Miller AH. Is depression an inflammatory disorder? Curr Psychiatry Rep. (2011) 13:467-75. doi: 10.1007/s11920-011-0232-0

55. Deguchi A. Curcumin targets in inflammation and cancer. Endocr Metab Immune Disord Drug Targets. (2015) 15:8896. doi: 10.2174/1871530315666150316120458

56. Aggarwal BB, Gupta SC, Sung B. Curcumin: an orally bioavailable blocker of TNF and other pro-inflammatory biomarkers. Br J Pharmacol. (2013) 169:1672-92. doi: 10.1111/bph.12131

57. Wang Z, Zhang Q, Yuan L, Wang S, Liu L, Yang X, et al. The effects of curcumin on depressive-like behavior in mice after lipopolysaccharide administration. Behav Brain Res. (2014) 274:282-90. doi: 10.1016/j.bbr.2014.08.018

58. Jangra A, Kwatra M, Singh T, Pant R, Kushwah P, Sharma Y, et al. Piperine augments the protective effect of curcumin against lipopolysaccharideinduced neurobehavioral and neurochemical deficits in mice. Inflammation. (2016) 39:1025-38. doi: 10.1007/s10753-016-0332-4

59. Fan C, Song Q, Wang P, Li Y, Yang M, Liu B, et al. Curcumin protects against chronic stress-induced dysregulation of neuroplasticity and depressionlike behaviors via suppressing IL-1 $\beta$ pathway in rats. Neuroscience. (2018) 392:92-106. doi: 10.1016/j.neuroscience.2018.09.028

60. Yu JJ, Pei LB, Zhang Y, Wen ZY, Yang JL. Chronic supplementation of curcumin enhances the efficacy of antidepressants in major depressive disorder: a randomized, double-blind, placebo-controlled pilot study. J Clin Psychopharmacol. (2015) 35:406-10. doi: 10.1097/JCP.0000000000000352

61. Sahebkar A. Are curcuminoids effective C-reactive protein-lowering agents in clinical practice? Evidence from a meta-analysis. Phytother Res. (2014) 28:633-42. doi: 10.1002/ptr.5045

62. Zhou H, Beevers CS, Huang S. Targets of curcumin. Curr Drug Targets. (2011) 12:332-47. doi: 10.2174/138945011794815356

63. Bauernfeind F, Horvath G, Stutz A, Alnemri ES, MacDonald K, Speert $\mathrm{D}$, et al. NF-kB activating pattern recognition and cytokine receptors license NLRP3 inflammasome activation by regulating NLRP3 expression. J Immunol. (2009) 183:787-91. doi: 10.4049/jimmunol.0901363

64. Kelley N, Jeltema D, Duan Y, He Y. The NLRP3 inflammasome: an overview of mechanisms of activation and regulation. Int J Mol Sci. (2019) 20:3328. doi: 10.3390/ijms20133328

65. Busillo JM, Azzam KM, Cidlowski JA. Glucocorticoids sensitize the innate immune system through regulation of the NLRP3 inflammasome. J Biol Chem. (2011) 286:38703-13. doi: 10.1074/jbc.M111.275370

66. Frank MG, Watkins LR, Maier SF. The permissive role of glucocorticoids in neuroinflammatory priming: mechanisms and insights. Curr Opin Endocrinol Diabetes Obes. (2015) 22:300-5. doi: 10.1097/MED.0000000000000168

67. Lamkanfi M, Mueller JL, Vitari AC, Misaghi S, Fedorova A, Deshayes K, et al. Glyburide inhibits the cryopyrin/Nalp3 inflammasome. J Cell Biol. (2009) 187:61-70. doi: 10.1083/jcb.200903124

68. Sperlágh B, Illes $\mathrm{P}$. P2X7 receptor: an emerging target in central nervous system diseases. Trends Pharmacol Sci. (2014) 35:537-47. doi: 10.1016/j.tips.2014.08.002

69. Heid ME, Keyel PA, Kamga C, Shiva S, Watkins SC, Salter RD. Mitochondrial ROS induces NLRP3-dependent lysosomal damage and inflammasome activation. J Immunol. (2013) 191:5230-8. doi: 10.4049/jimmunol.1301490

70. Alcocer-Gómez E, Ulecia-Morón C, Marín-Aguilar F, Rybkina T, CasasBarquero N, Ruiz-Cabello J, et al. Stress-induced depressive behaviors require a functional NLRP3 inflammasome. Mol Neurobiol. (2016) 53:487482. doi: 10.1007/s12035-015-9408-7

71. Lu M, Yang JZ, Geng F, Ding JH, Hu G. Iptakalim confers an antidepressant effect in a chronic mild stress model of depression through regulating neuro-inflammation and neurogenesis. Int J Neuropsychopharmacol. (2014) 17:1501-10. doi: 10.1017/S1461145714000285

72. Pan Y, Chen X-Y, Zhang Q-Y, Kong L-D. Microglial NLRP3 inflammasome activation mediates IL-1 $\beta$-related inflammation in prefrontal cortex of depressive rats. Brain Behav Immun. (2014) 41:90-100. doi: 10.1016/j.bbi.2014.04.007
73. Ozkartal SC, Tuzun E, Kucukali CI, Ulusoy C, Giris M, Aricioglu F. Antidepressant-like effects of agmatine and NOS inhibitors in chronic unpredictable mild stress model of depression in rats: the involvement of NLRP inflammasomes. Brain Res. (2019) 1725:146438. doi: 10.1016/j.brainres.2019.146438

74. Alcocer-Gómez E, de Miguel M, Casas-Barquero N, Núñez-Vasco J, SánchezAlcazar JA, Fernández-Rodríguez A, et al. NLRP3 inflammasome is activated in mononuclear blood cells from patients with major depressive disorder. Brain Behav Immun. (2014) 36:111-7. doi: 10.1016/j.bbi.2013.10.017

75. Li Y, Li J, Li S, Li Y, Wang X, Liu B, et al. Curcumin attenuates glutamate neurotoxicity in the hippocampus by suppression of ER stress-associated TXNIP/NLRP3 inflammasome activation in a manner dependent on AMPK. Toxicol Appl Pharmacol. (2015) 286:53-63. doi: 10.1016/j.taap.2015.03.010

76. Fan C, Song Q, Wang P, Li Y, Yang M, Yu SY. Neuroprotective effects of curcumin on IL-1 $\beta$-induced neuronal apoptosis and depression-like behaviors caused by chronic stress in rats. Front Cell Neurosci. (2019) 12:516. doi: $10.3389 /$ fncel.2018.00516

77. Zhang W, Guo Y, Han W, Yang M, Wen L, Wang K, et al. Curcumin relieves depressive-like behaviors via inhibition of the NLRP3 inflammasome and kynurenine pathway in rats suffering from chronic unpredictable mild stress. Int Immunopharmacol. (2019) 67:138-44. doi: 10.1016/j.intimp.2018.12.012

78. Wang Z, Ren W, Zhao F, Han Y, Liu C, Jia K. Curcumin amends Ca2+ dysregulation in microglia by suppressing the activation of $\mathrm{P} 2 \mathrm{X} 7$ receptor. Mol Cell Biochem. (2020) 465:65-73. doi: 10.1007/s11010-019-03668-8

79. Dhir A, Kulkarni SK. Nitric oxide and major depression. Nitric Oxide. (2011) 24:125-31. doi: 10.1016/j.niox.2011.02.002

80. Wegener G, Volke V. Nitric oxide synthase inhibitors as antidepressants. Pharmaceuticals. (2010) 3:273-99. doi: 10.3390/ph3010273

81. Lee BH, Lee SW, Yoon D, Lee HJ, Yang JC, Shim SH, et al. Increased plasma nitric oxide metabolites in suicide attempters. NPS. (2006) 53:12732. doi: $10.1159 / 000092542$

82. Suzuki E, Yagi G, Nakaki T, Kanba S, Asai M. Elevated plasma nitrate levels in depressive states. J Affect Disord. (2001) 63:2214. doi: 10.1016/S0165-0327(00)00164-6

83. Chen HJC, Spiers JG, Sernia C, Lavidis NA. Response of the nitrergic system to activation of the neuroendocrine stress axis. Front Neurosci. (2015) 9:3. doi: 10.3389/fnins.2015.00003

84. Gawali NB, Bulani VD, Gursahani MS, Deshpande PS, Kothavade PS, Juvekar AR. Agmatine attenuates chronic unpredictable mild stressinduced anxiety, depression-like behaviours and cognitive impairment by modulating nitrergic signalling pathway. Brain Res. (2017) 1663:6677. doi: 10.1016/j.brainres.2017.03.004

85. Braidy N, Grant R, Adams S, Guillemin GJ. Neuroprotective effects of naturally occurring polyphenols on quinolinic acidinduced excitotoxicity in human neurons. FEBS J. (2010) 277:368-82. doi: 10.1111/j.1742-4658.2009.07487.x

86. Gilhotra N, Dhingra D. GABAergic and nitriergic modulation by curcumin for its antianxiety-like activity in mice. Brain Res. (2010) 1352:16775. doi: 10.1016/j.brainres.2010.07.007

87. Wei S, Xu H, Xia D, Zhao R. Curcumin attenuates the effects of transport stress on serum cortisol concentration, hippocampal NO production, and BDNF expression in the pig. Domest Anim Endocrinol. (2010) 39:2319. doi: 10.1016/j.domaniend.2010.06.004

88. Stone TW, Forrest CM, Darlington LG. Kynurenine pathway inhibition as a therapeutic strategy for neuroprotection. FEBS J. (2012) 279:138697. doi: 10.1111/j.1742-4658.2012.08487.x

89. Maes M, Leonard BE, Myint AM, Kubera M, Verkerk R. The new '5-HT' hypothesis of depression: Cell-mediated immune activation induces indoleamine 2,3-dioxygenase, which leads to lower plasma tryptophan and an increased synthesis of detrimental tryptophan catabolites (TRYCATs), both of which contribute to the onset of depression. Prog Neuro Psychopharmacol Biol Psychiatry. (2011) 35:702-21. doi: 10.1016/j.pnpbp.2010.12.017

90. Qin Y, Wang N, Zhang X, Han X, Zhai X, Lu Y. IDO and TDO as a potential therapeutic target in different types of depression. Metab Brain Dis. (2018) 33:1787-800. doi: 10.1007/s11011-018-0290-7

91. Young KD, Drevets WC, Dantzer R, Teague TK, Bodurka J, Savitz J. Kynurenine pathway metabolites are associated with hippocampal activity 
during autobiographical memory recall in patients with depression. Brain Behav Immun. (2016) 56:335-42. doi: 10.1016/j.bbi.2016.04.007

92. Ogyu K, Kubo K, Noda Y, Iwata Y, Tsugawa S, Omura Y, et al. Kynurenine pathway in depression: A systematic review and meta-analysis. Neurosci Biobehav Rev. (2018) 90:16-25. doi: 10.1016/j.neubiorev.2018.03.023

93. Verdonk F, Petit AC, Abdel-Ahad P, Vinckier F, Jouvion G, de Maricourt P, et al. Microglial production of quinolinic acid as a target and a biomarker of the antidepressant effect of ketamine. Brain Behav Immun. (2019) 81:36173. doi: $10.1016 /$ j.bbi.2019.06.033

94. Myint AM. Kynurenines: from the perspective of major psychiatric disorders. FEBS J. (2012) 279:137585. doi: 10.1111/j.1742-4658.2012.08551.x

95. Jeong YI, Kim SW, Jung ID, Lee JS, Chang JH, Lee CM, et al. Curcumin suppresses the induction of indoleamine 2,3-dioxygenase by blocking the janus-activated kinase-protein kinase C $\delta$-STAT1 signaling pathway in interferon- $\gamma$-stimulated murine dendritic cells. J Biol Chem. (2009) 284:3700-8. doi: 10.1074/jbc.M807328200

96. Cesario A, Rutella BRS. The Iinterplay between indoleamine 2,3-dioxygenase 1 (IDO1) and cyclooxygenase (COX)- 2 in chronic inflammation and cancer. Curr nt Med Chem. (2011) 18:2263-71. doi: 10.2174/092986711795656063

97. Calabrese JR, Skwerer RG, Barna B, Gulledge AD, Valenzuela R, Butkus A, et al. Depression, immunocompetence, and prostaglandins of the $\mathrm{E}$ series. Psychiatry Res. (1986) 17:41-7. doi: 10.1016/0165-1781(86)90040-5

98. Ohishi K, Ueno R, Nishino S, Sakai T, Hayaishi O. Increased level of salivary prostaglandins in patients with major depression. Biol Psychiatry. (1988) 23:326-34. doi: 10.1016/0006-3223(88)90283-1

99. Gałecki P, Talarowska M, Bobińska K, Szemraj J. COX-2 gene expression is correlated with cognitive function in recurrent depressive disorder. Psychiatry Res. (2014) 215:488-90. doi: 10.1016/j.psychres.2013.12.017

100. Faridhosseini F, Sadeghi R, Farid L, Pourgholami M. Celecoxib: a new augmentation strategy for depressive mood episodes. A systematic review and meta-analysis of randomized placebo-controlled trials. Hum Psychopharmacol. (2014) 29:216-23. doi: 10.1002/hup.2401

101. Abbasi SH, Hosseini F, Modabbernia A, Ashrafi M, Akhondzadeh S. Effect of celecoxib add-on treatment on symptoms and serum IL-6 concentrations in patients with major depressive disorder: Randomized double-blind placebo-controlled study. J Affect Disord. (2012) 141:30814. doi: $10.1016 /$ j.jad.2012.03.033

102. Lee KH, Abas F, Alitheen NBM, Shaari K, Lajis NH, Ahmad S. A curcumin derivative, 2,6-bis(2,5-dimethoxybenzylidene)-cyclohexanone (BDMC33) attenuates prostaglandin E2 synthesis via selective suppression of cyclooxygenase- 2 in IFN- $\gamma /$ LPS-stimulated macrophages. Molecules. (2011) 16:9728-38. doi: 10.3390/molecules 16119728

103. Choi GY, Kim HB, Hwang ES, Lee S, Kim MJ, Choi JY, et al. Curcumin alters neural plasticity and viability of intact hippocampal circuits and attenuates behavioral despair and COX-2 expression in chronically stressed rats. Mediators Inflamm. (2017) 2017:6280925. doi: 10.1155/2017/6280925

104. Sorokin A. Nitric oxide synthase and cyclooxygenase pathways: a complex interplay in cellular signaling. Curr Med Chem. (2016) 23:255978. doi: 10.2174/0929867323666160729105312

105. Fasano A, Shea-Donohue T. Mechanisms of disease: the role of intestinal barrier function in the pathogenesis of gastrointestinal autoimmune diseases. Nat Rev Gastroenterol Hepatol. (2005) 2:416-22. doi: $10.1038 /$ ncpgasthep0259

106. Miller AL. The pathogenesis, clinical implications, and treatment of intestinal hyperpermeability. Alternat Med Rev. (1997) 2:16.

107. Maes M, Kubera M, Leunis JC. The gut-brain barrier in major depression: Intestinal mucosal dysfunction with an increased translocation of LPS from gram negative enterobacteria (leaky gut) plays a role in the inflammatory pathophysiology of depression. Neuro Endocrinol Lett. (2008) 29:117-24.

108. Qin L, Wu X, Block ML, Liu Y, Breese GR, Hong JS, et al. Systemic LPS causes chronic neuroinflammation and progressive neurodegeneration. Glia. (2007) 55:453-62. doi: 10.1002/glia.20467

109. Dobos N, de Vries EFJ, Kema IP, Patas K, Prins M, Nijholt IM, et al. The role of indoleamine 2,3-dioxygenase in a mouse model of neuroinflammation-induced depression. J Alzheimer's Dis. (2012) 28:90515. doi: 10.3233/JAD-2011-111097
110. Fu X, Zunich SM, O'Connor JC, Kavelaars A, Dantzer R, Kelley KW. Central administration of lipopolysaccharide induces depressive-like behavior in vivo and activates brain indoleamine 2,3 dioxygenase in murine organotypic hippocampal slice cultures. J Neuroinflammation. (2010) 7:43. doi: 10.1186/1742-2094-7-43

111. O'Connor JC, Lawson MA, André C, Moreau M, Lestage J, Castanon N, et al. Lipopolysaccharide-induced depressive-like behavior is mediated by indoleamine 2,3-dioxygenase activation in mice. Mol Psychiatry. (2009) 14:511-22. doi: 10.1038/sj.mp.4002148

112. Maes M, Kubera M, Leunis JC, Berk M. Increased IgA and IgM responses against gut commensals in chronic depression: Further evidence for increased bacterial translocation or leaky gut. J Affect Disord. (2012) 141:5562. doi: 10.1016/j.jad.2012.02.023

113. Wang J, Ghosh SS, Ghosh S. Curcumin improves intestinal barrier function: modulation of intracellular signaling, and organization of tight junctions. Am J Physiol Cell Physiol. (2017) 312:C438-45. doi: 10.1152/ajpcell.00235.2016

114. Pariante CM, Lightman SL. The HPA axis in major depression: classical theories and new developments. Trends Neurosci. (2008) 31:464-8. doi: 10.1016/j.tins.2008.06.006

115. Nemeroff CB, Krishnan KRR, Reed D, Leder R, Beam C, Dunnick NR. Adrenal gland enlargement in major depression: a computed tomographic study. Arch Gen Psychiatry. (1992) 49:384-7. doi: 10.1001/archpsyc.1992.01820050048008

116. Rinwa P, Kumar A. Piperine potentiates the protective effects of curcumin against chronic unpredictable stress-induced cognitive impairment and oxidative damage in mice. Brain Res. (2012) 1488:38-50. doi: 10.1016/j.brainres.2012.10.002

117. Xu Y, Li S, Vernon MM, Pan J, Chen L, Barish PA, et al. Curcumin prevents corticosterone-induced neurotoxicity and abnormalities of neuroplasticity via 5-HT receptor pathway. J Neurochem. (2011) 118:784-95. doi: 10.1111/j.1471-4159.2011.07356.x

118. Xu Y, Ku B, Tie L, Yao H, Jiang W, Ma X, et al. Curcumin reverses the effects of chronic stress on behavior, the HPA axis, BDNF expression and phosphorylation of CREB. Brain Res. (2006) 1122:5664. doi: 10.1016/j.brainres.2006.09.009

119. Ghasemi R, Haeri A, Dargahi L, Mohamed Z, Ahmadiani A. Insulin in the brain: sources, localization and functions. Mol Neurobiol. (2013) 47:14571. doi: 10.1007/s12035-012-8339-9

120. Stockhorst U, de Fries D, Steingrueber HJ, Scherbaum WA. Insulin and the CNS: effects on food intake, memory, and endocrine parameters and the role of intranasal insulin administration in humans. Physiol Behav. (2004) 83:47-54. doi: 10.1016/S0031-9384(04)00348-8

121. Zhao W-Q, Alkon DL. Role of insulin and insulin receptor in learning and memory. Mol Cell Endocrinol. (2001) 177:12534. doi: 10.1016/S0303-7207(01)00455-5

122. Blázquez E, Velázquez E, Hurtado-Carneiro V, Ruiz-Albusac JM. Insulin in the Brain: Its pathophysiological implications for states related with central insulin resistance, type 2 diabetes and Alzheimer's disease. Front Endocrinol. (2014) 5:161. doi: 10.3389/fendo.2014.00161

123. Ford AH, Flicker L, Hankey GJ, Yeap BB, Chubb SAP, Golledge J, et al. Insulin resistance and depressive symptoms in older men: the health in men study. Am J Geriatr Psychiatry. (2015) 23:872-80. doi: 10.1016/j.jagp.2014. 10.010

124. Kan C, Silva N, Golden SH, Rajala U, Timonen M, Stahl D, et al. A systematic review and meta-analysis of the association between depression and insulin resistance. Diabetes Care. (2013) 36:480-9. doi: 10.2337/dc12-1442

125. Benedict C, Grillo CA. Insulin resistance as a therapeutic target in the treatment of Alzheimer's disease: A state-of-the-art review. Front Neurosci. (2018) 12:215. doi: 10.3389/fnins.2018.00215

126. Kleinridders A, Cai W, Cappellucci L, Ghazarian A, Collins WR, Vienberg SG, et al. Insulin resistance in brain alters dopamine turnover and causes behavioral disorders. Proc Natl Acad Sci USA. (2015) 112:34638. doi: 10.1073/pnas.1500877112

127. Asghar A, Sheikh N. Role of immune cells in obesity induced low grade inflammation and insulin resistance. Cell Immunol. (2017) 315:1826. doi: 10.1016/j.cellimm.2017.03.001 
128. Tiganis T. Reactive oxygen species and insulin resistance: the good, the bad and the ugly. Trends Pharmacol Sci. (2011) 32:82-9. doi: 10.1016/j.tips.2010.11.006

129. Dandona P, Chaudhuri A, Ghanim H, Mohanty P. Proinflammatory effects of glucose and anti-inflammatory effect of insulin: relevance to cardiovascular disease. Am J Cardiol. (2007) 99:15-26. doi: 10.1016/j.amjcard.2006.11.003

130. Leonard BE, Wegener G. Inflammation, insulin resistance and neuroprogression in depression. Acta Neuropsychiatr. (2020) 32:1-9. doi: 10.1017/neu.2019.17

131. Yaribeygi $H$, Ashrafizadeh $M$, Henney NC, Sathyapalan $T$, Jamialahmadi T, Sahebkar A. Neuromodulatory effects of antidiabetes medications: A mechanistic review. Pharmacol Res. (2020) 152:104611. doi: 10.1016/j.phrs.2019.104611

132. Shen JD, Wei Y, Li YJ, Qiao JY, Li YC. Curcumin reverses the depressive-like behavior and insulin resistance induced by chronic mild stress. Metab Brain Dis. (2017) 32:1163-72. doi: 10.1007/s11011-017-0017-1

133. Den Hartogh DJ, Gabriel A, Tsiani E. Antidiabetic properties of curcumin II: evidence from in vivo studies. Nutrients. (2019) 12:58. doi: $10.3390 /$ nu12010058

134. Lee BH, Kim YK. The Roles of BDNF in the pathophysiology of major depression and in antidepressant treatment. Psychiatry Investig. (2010) 7:231-5. doi: 10.4306/pi.2010.7.4.231

135. Zoladz JA, Pilc A. The effect of physical activity on the brain derived neurotrophic factor: from animal to human studies. J Physiol Pharmacol. (2010) 61:533-41.

136. Björkholm C, Monteggia LM. BDNF - a key transducer of antidepressant effects. Neuropharmacology. (2016) 102:729. doi: 10.1016/j.neuropharm.2015.10.034

137. Rocha RB, Dondossola ER, Grande AJ, Colonetti T, Ceretta LB, Passos IC, et al. Increased BDNF levels after electroconvulsive therapy in patients with major depressive disorder: a meta-analysis study. J Psychiatr Res. (2016) 83:47-53. doi: 10.1016/j.jpsychires.2016.08.004

138. Malhi GS, Tanious M, Das P, Coulston CM, Berk M. Potential mechanisms of action of lithium in bipolar disorder. CNS Drugs. (2013) 27:13553. doi: 10.1007/s40263-013-0039-0

139. Volmat V, Pouysségur J. Spatiotemporal regulation of the p42/p44 MAPK pathway. Biol Cell. (2001) 93:71-9. doi: 10.1016/S0248-4900(01)01129-7

140. Wang JQ, Mao L. The ERK pathway: molecular mechanisms and treatment of depression. Mol Neurobiol. (2019) 56:6197205. doi: 10.1007/s12035-019-1524-3

141. Hurley LL, Akinfiresoye L, Nwulia E, Kamiya A, Kulkarni A, Tizabi Y. Antidepressant-like effects of curcumin in WKY rat model of depression is associated with an increase in hippocampal BDNF. Behav Brain Res. (2013) 239:27-30. doi: 10.1016/j.bbr.2012.10.049

142. Liu D, Wang Z, Gao Z, Xie K, Zhang Q, Jiang H, et al. Effects of curcumin on learning and memory deficits, BDNF, and ERK protein expression in rats exposed to chronic unpredictable stress. Behav Brain Res. (2014) 271:11621. doi: 10.1016/j.bbr.2014.05.068

143. Zhang L, Xu T, Wang S, Yu L, Liu D, Zhan R, et al. Curcumin produces antidepressant effects via activating MAPK/ERK-dependent brain-derived neurotrophic factor expression in the amygdala of mice. Behav Brain Res. (2012) 235:67-72. doi: 10.1016/j.bbr.2012.07.019

144. Zhang L, Luo J, Zhang $M$, Yao W, Ma X, Yu SY. Effects of curcumin on chronic, unpredictable, mild, stress-induced depressive-like behaviour and structural plasticity in the lateral amygdala of rats. Int J Neuropsychopharmacol. (2014) 17:793-806. doi: 10.1017/S1461145713001661

145. Abd-Rabo MM, Georgy GS, Saied NM, Hassan WA. Involvement of the serotonergic system and neuroplasticity in the antidepressant effect of curcumin in ovariectomized rats: comparison with oestradiol and fluoxetine. Phytother Res. (2019) 33:387-96. doi: 10.1002/pt r.6232

146. Lushchak VI. Free radicals, reactive oxygen species, oxidative stress and its classification. Chem Biol Interact. (2014) 224:16475. doi: 10.1016/j.cbi.2014.10.016

147. Bilici M, Efe H, Köroglu MA, Uydu HA, Bekaroglu M, Deger O. Antioxidative enzyme activities and lipid peroxidation in major depression: alterations by antidepressant treatments. J Affect Disord. (2001) 64:4351. doi: 10.1016/S0165-0327(00)00199-3

148. Shafiee M, Ahmadnezhad M, Tayefi M, Arekhi S, Vatanparast H, Esmaeili $\mathrm{H}$, et al. Depression and anxiety symptoms are associated with prooxidantantioxidant balance: a population-based study. J Affect Disord. (2018) 238:491-8. doi: 10.1016/j.jad.2018.05.079

149. Fernandes BS, Dean OM, Dodd S, Malhi GS, Berk M. N-Acetylcysteine in depressive symptoms and functionality: a systematic review and metaanalysis. J Clin Psychiatry. (2016) 77:e457-466. doi: 10.4088/JCP.15r09984

150. Naqvi F, Saleem S, Naqvi F, Batool Z, Sadir S, Tabassum S, et al. Curcumin lessens unpredictable chronic mild stress-induced depression and memory deficits by modulating oxidative stress and cholinergic activity. Pak J Pharm Sci. (2019) 32:1893-900.

151. Fidelis EM, Savall ASP, da Luz Abreu E, Carvalho F, Teixeira FEG, Haas SE, et al. Curcumin-loaded nanocapsules reverses the depressant-like behavior and oxidative stress induced by $\beta$-amyloid in mice. Neuroscience. (2019) 423:122-30. doi: 10.1016/j.neuroscience.2019.09.032

152. Svízenská I, Dubový P, Sulcová A. Cannabinoid receptors 1 and 2 (CB1 and $\mathrm{CB} 2$ ), their distribution, ligands and functional involvement in nervous system structures-a short review. Pharmacol Biochem Behav. (2008) 90:50111. doi: 10.1016/j.pbb.2008.05.010

153. Mackie K. Cannabinoid receptors: where they are and what they do. $J$ Neuroendocrinol. (2008) 20:10-4. doi: 10.1111/j.1365-2826.2008.01671.x

154. Williamson EM, Evans FJ. Cannabinoids in clinical practice. Drugs. (2000) 60:1303-14. doi: 10.2165/00003495-200060060-00005

155. Bisogno T, Berrendero F, Ambrosino G, Cebeira M, Ramos JA, FernandezRuiz JJ, et al. Brain regional distribution of endocannabinoids: implications for their biosynthesis and biological function. Biochem Biophys Res Commun. (1999) 256:377-80. doi: 10.1006/bbrc.1999.0254

156. Hill MN, McLaughlin RJ, Bingham B, Shrestha L, Lee TTY, Gray JM, et al. Endogenous cannabinoid signaling is essential for stress adaptation. Proc Natl Acad Sci USA. (2010) 107:9406-11. doi: 10.1073/pnas.0914661107

157. Hill MN, Gorzalka BB. Impairments in endocannabinoid signaling and depressive illness. JAMA. (2009) 301:1165-6. doi: 10.1001/jama.2009.369

158. Horder J, Cowen PJ, Di Simplicio M, Browning M, Harmer CJ. Acute administration of the cannabinoid CB1 antagonist rimonabant impairs positive affective memory in healthy volunteers. Psychopharmacology. (2009) 205:85-91. doi: 10.1007/s00213-009-1517-4

159. Steffens M, Feuerstein T. Receptor-independent depression of DA and 5HT uptake by cannabinoids in rat neocortex-Involvement of $\mathrm{Na}(+) / \mathrm{K}(+)$ ATPase. Neurochem Int. (2004) 44:529-38. doi: 10.1016/j.neuint.2003.08.009

160. He X, Zhu Y, Wang M, Jing G, Zhu R, Wang S. Antidepressant effects of curcumin and HU-211 coencapsulated solid lipid nanoparticles against corticosterone-induced cellular and animal models of major depression. Int J Nanomedicine. (2016) 11:4975-90. doi: 10.2147/IJN.S109088

161. Hassanzadeh P, Hassanzadeh A. The CB1 receptor-mediated endocannabinoid signaling and NGF: the novel targets of curcumin. Neurochem Res. (2012) 37:1112-20. doi: 10.1007/s11064-012-0716-2

162. Witkin JM, Leucke S, Thompson LK, Lynch RA, Ding C, Heinz B, et al. Further evaluation of the neuropharmacological determinants of the antidepressant-like effects of curcumin. CNS Neurol Disord Drug Targets. (2013) 12:498-505. doi: 10.2174/18715273113120 40008

163. Ng QX, Koh SSH, Chan HW, Ho CYX. Clinical use of curcumin in depression: a meta-analysis. J Am Med Dir Assoc. (2017) 18:5038. doi: 10.1016/j.jamda.2016.12.071

164. Prasad S, Tyagi AK, Aggarwal BB. Recent developments in delivery, bioavailability, absorption and metabolism of curcumin: the golden pigment from golden spice. Cancer Res Treat. (2014) 46:2-18. doi: 10.4143/crt.2014.46.1.2

165. Pulido-Moran M, Moreno-Fernandez J, Ramirez-Tortosa C, Ramirez-Tortosa Mc. Curcumin and health. Molecules. (2016) 21:264. doi: 10.3390/molecules21030264

166. Lao CD, Ruffin MT, Normolle D, Heath DD, Murray SI, Bailey JM, et al. Dose escalation of a curcuminoid formulation. BMC Complement Altern Med. (2006) 6:10. doi: 10.1186/1472-6882-6-10

167. Lopresti AL, Drummond PD. Efficacy of curcumin, and a saffron/curcumin combination for the treatment of major depression: a randomised, 
double-blind, placebo-controlled study. J Affect Disord. (2017) 207:18896. doi: 10.1016/j.jad.2016.09.047

168. Lopresti AL, Maes M, Maker GL, Hood SD, Drummond PD. Curcumin for the treatment of major depression: A randomised, double-blind, placebo controlled study. J Affect Disord. (2014) 167:368-75. doi: 10.1016/j.jad.2014.06.001

169. Tayyem RF, Heath DD, Al-Delaimy WK, Rock CL. Curcumin content of turmeric and curry powders. Nutr Cancer. (2006) 55:126-31. doi: 10.1207/s15327914nc5502_2

170. Ng TP, Chiam PC, Lee T, Chua HC, Lim L, Kua EH. Curry consumption and cognitive function in the elderly. Am J Epidemiol. (2006) 164:898906. doi: 10.1093/aje/kwj267

171. Burapan S, Kim M, Han J. Curcuminoid demethylation as an alternative metabolism by human intestinal microbiota. J Agric Food Chem. (2017) 65:3305-10. doi: 10.1021/acs.jafc.7b00943

172. Adiwidjaja J, McLachlan AJ, Boddy AV. Curcumin as a clinically-promising anti-cancer agent: pharmacokinetics and drug interactions. Expert Opin Drug Metab Toxicol. (2017) 13:953-72. doi: 10.1080/17425255.2017.1360279

173. Lopresti AL, Maes M, Meddens MJM, Maker GL, Arnoldussen E, Drummond PD. Curcumin and major depression: a randomised, double-blind, placebo-controlled trial investigating the potential of peripheral biomarkers to predict treatment response and antidepressant mechanisms of change. European Neuropsychopharmacology. (2015) 25:38-50. doi: 10.1016/j.euroneuro.2014.11.015

174. Xiao QC, Dui D, Lan TG. Effects of qingyi II granules on intestinal bacterial translocation in rats with acute necrotizing pancreatitis. Chin J Integr Tradit West Med. (2010) 26: 317-24. doi: 10.3978/j.issn.1005-6947.2017.03.008

175. Piechota A, Polańczyk A, Goraca A. Role of endothelin-1 receptor blockers on hemodynamic parameters and oxidative stress. Pharmacol Rep. (2010) 62:28-34. doi: 10.1016/S1734-1140(10)70240-1

176. Lange M, Pagotto U, Renner U, Arzberger T, Oeckler R, Stalla GK. The role of endothelins in the regulation of pituitary function. Exp Clin Endocrinol Diabetes. (2002) 110:103-12. doi: 10.1055/s-2002-29086

177. Giordano N, Papakostas P, Pecetti G, Nuti R. Cytokine modulation by endothelin-1 and possible therapeutic implications in systemic sclerosis. J Biol Regul Homeost Agents. (2011) 25:487-92.
178. Sanmukhani J, Satodia V, Trivedi J, Patel T, Tiwari D, Panchal B, et al. Efficacy and safety of curcumin in major depressive disorder: a randomized controlled trial. Phytother Res. (2014) 28:579-85. doi: 10.1002/ptr. 5025

179. Asadi S, Gholami MS, Siassi F, Qorbani M, Sotoudeh G. Beneficial effects of nano-curcumin supplement on depression and anxiety in diabetic patients with peripheral neuropathy: a randomized, double-blind, placebocontrolled clinical trial. Phytother Res. (2020) 34:896-903. doi: 10.1002/ptr. 6571

180. Setiawati MC, Ikawati Z, Kertia IN. Antiinflamatory and antidepressive activities of extract Curcuma xanthorrhiza roxb in systemic lupus Erythematosus. Indones $J$ Pharm. (2017) 28:185. doi: 10.14499/indonesianjpharm28iss3 pp185

181. Kappelmann N, Lewis G, Dantzer R, Jones PB, Khandaker GM. Antidepressant activity of anti-cytokine treatment: a systematic review and meta-analysis of clinical trials of chronic inflammatory conditions. Mol Psychiatry. (2018) 23:335-43. doi: 10.1038/mp.20 16.167

182. Raison CL, Rutherford RE, Woolwine BJ, Shuo C, Schettler P, Drake $\mathrm{DF}$, et al. A randomized controlled trial of the tumor necrosis factoralpha antagonist infliximab in treatment resistant depression: role of baseline inflammatory biomarkers. JAMA Psychiatry. (2013) 70:3141. doi: 10.1001/2013.jamapsychiatry.4

Conflict of Interest: The authors declare that the research was conducted in the absence of any commercial or financial relationships that could be construed as a potential conflict of interest.

Copyright (๑ 2020 Ramaholimihaso, Bouazzaoui and Kaladjian. This is an openaccess article distributed under the terms of the Creative Commons Attribution License (CC BY). The use, distribution or reproduction in other forums is permitted, provided the original author(s) and the copyright owner(s) are credited and that the original publication in this journal is cited, in accordance with accepted academic practice. No use, distribution or reproduction is permitted which does not comply with these terms. 